\title{
Rapid Extraction of Dissolved Inorganic Carbon from Seawater and Groundwater Samples for Radiocarbon Dating
}

\section{By}

\author{
Kalina Doneva Gospodinova
}

Submitted in partial fulfillment of the requirements for the degree of

Master of Science in Mechanical Engineering

at the

\section{MASSSACHUSETTS INSTITUTE OF TECHNOLOGY \\ and the \\ WOODS HOLE OCEANOGRAPHIC INSTITUTION}

June 2012

(C) 2012 Kalina Gospodinova - All rights reserved.

The author hereby grants to MIT and WHOI permission to reproduce and to distribute publicly paper and electronic copies of this thesis document

in whole or in part in any medium now known or hereafter created.

Signature of Author

Joint Program in Oceanography/Applied Ocean Science and Engineering Massachusetts Institute of Technology and Woods Hole Oceanographic Institution

May 11, 2012

Certified by

Ann McNichol

Thesis Supervisor

Senior Research Specialist

Geology \& Geophysics, Woods Hole Oceanographic Institution

Accepted by

David E. Hardt

Chairman, Departmental Committee on Graduate Students

Department of Mechanical Engineering, Massachusetts Institute of Technology

Accepted by

Henrik Schmidt

Chair, MIT/WHOI Joint Committee for Applied Ocean Science and Engineering Massachusetts Institute of Technology/Woods Hole Oceanographic Institution 


\title{
Rapid Extraction of Dissolved Inorganic Carbon from Seawater and Groundwater Samples for Radiocarbon Dating
}

\author{
By
}

\author{
Kalina Doneva Gospodinova
}

\begin{abstract}
Submitted to the Joint Program in Oceanography/Applied Ocean Science and Engineering on May 11, 2012, in partial fulfillment of the requirements for the degree of Master of Science in Mechanical Engineering
\end{abstract}

\begin{abstract}
The focus of this thesis is the design and development of a system for rapid extraction of dissolved inorganic carbon from seawater and groundwater samples for radiocarbon dating. The Rapid Extraction of Dissolved Inorganic Carbon System (REDICS) consists of two subsystems - one for sample introduction, acidification, and carbon dioxide extraction, and one for carbon dioxide quantification and storing. The first subsystem efficiently extracts the dissolved inorganic carbon from the water sample in the form of carbon dioxide by utilizing a gas-permeable polymer membrane contractor. The second subsystem traps, quantifies and stores the extracted gas using cryogenics. The extracted carbon dioxide is further processed for stable and radiocarbon isotope analysis at the National Ocean Sciences Accelerator Mass Spectrometer Facility at the Woods Hole Oceanographic Institution.

The REDICS system was tested using seawater standards collected at $470 \mathrm{~m}$ and $4000 \mathrm{~m}$ depth in the Atlantic Ocean and analyzing the extracted $\mathrm{CO}_{2}$. The results were compared to the results for the same standards processed on the current NOSAMS water stripping line. The results demonstrate that the system successfully extracts more than $99 \%$ of the dissolved inorganic carbon in less than 20 minutes. Stable isotope and radiocarbon isotope analyses demonstrated system precision of $0.02 \%$ and $3.5 \%$ respectively.
\end{abstract}

Thesis Supervisor: Ann McNichol

Title: Senior Research Specialist Geology \& Geophysics, Woods Hole Oceanographic Institution 


\section{Acknowledgements}

I would like to thank my advisor Dr. Ann McNichol for the unlimited support and encouragement she has given me during my graduate career, and for her great sense of humor.

I would also like to thank Al Gagnon for his help in performing stable isotope analysis on all my samples as soon as I collected them, no matter the date or time.

To my colleague and friend Dr. Cameron McIntyre, thank you for being there for me throughout my entire graduate career and always rescuing me in times of need.

Thank you to Dr. Bill Jenkins for his data analysis input, Dr. Steven Beaupre for teaching me basic glass blowing techniques needed for this work, and the rest of my colleagues and friends at NOSAMS for their unlimited help, support, and patience.

My graduate studies and research were funded by the National Science Foundation as well as the MIT WHOI Joint Program, and I am very grateful for their support.

To Tricia Gebbie, Julia Westwater, Marsha Gomes Armando and the rest of the APO office at WHOI, as well as Leslie Regan, Joan Kravit, and Ronni Swarts at MIT, thank you for never leaving any logistics question I had unanswered.

I would also like to thank Dr. Meg Tivey for always having time to listen.

Lastly I would like to thank my family and friends for their love and support. 


\section{CONTENTS}

1. INTRODUCTION AND BACKGROUND ......................................................... 9

1.1. ${ }^{14} \mathrm{C}$ measurements and their importance ....................................................9 9

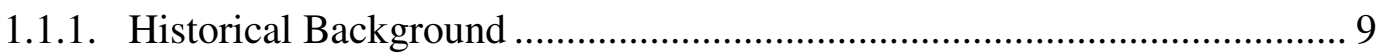

1.1.2. Radiocarbon in climate change and ocean circulation............................ 10

1.2. Current NOSAMS DIC line design ......................................................... 11

1.3. New proposed extraction method ............................................................... 12

2. MEMBRANE EXTRACTION TECHNOLOGY ........................................ 13

2.1. Membrane types................................................................................................................ 13

2.1.1. Gas separation membranes ........................................................... 13

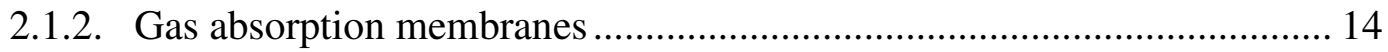

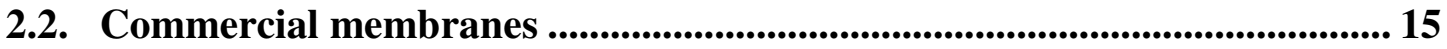

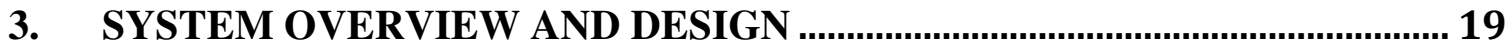

3.1. System overview and objectives............................................................. 19

3.2. Operation principles ............................................................................ 19

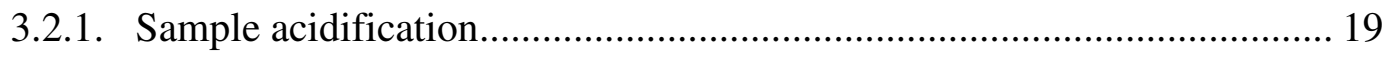

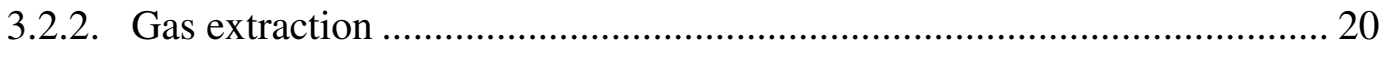

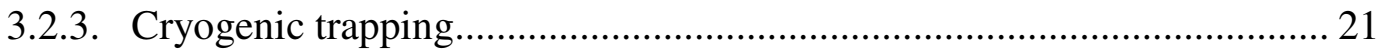

3.3. System component description and operation .............................................. 21

3.3.1. Sample introduction, acidification, and $\mathrm{CO}_{2}$ extraction subsystem.......... 22

3.3.2. $\mathrm{CO}_{2}$ trapping, quantification and storing subsystem............................. 26

4. CALIBRATION AND VALIDATION PROCEDURES ................................... 29

4.1. Membrane performance................................................................................................. 29

4.2. $\mathrm{CO}_{2}$ trap volume calibration ..................................................................................... 31

4.3. $\mathrm{CO}_{2}$ trap performance validation............................................................................. 32 
4.4. Full system validation procedure ........................................................................... 32

4.4.1. Seawater $\delta^{13} \mathrm{C}$ measurements.................................................................. 33

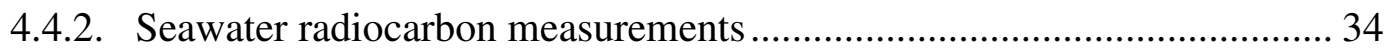

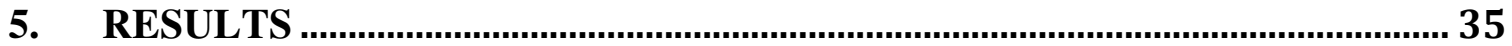

5.1. Data analysis................................................................................................................... 35

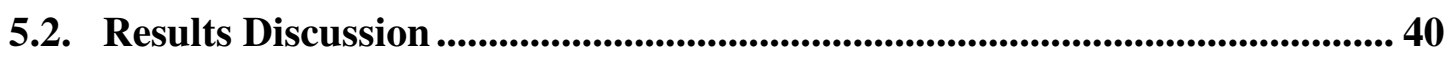

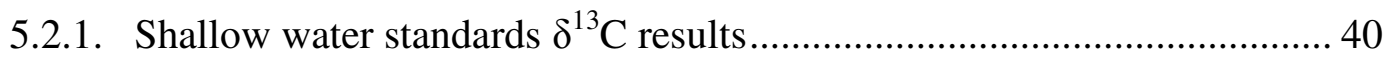

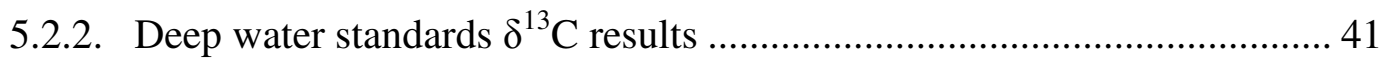

5.2.3. Deep water standards fm results ............................................................ 44

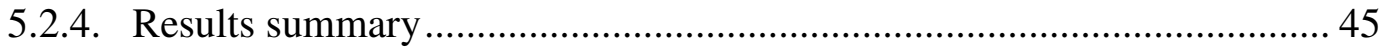

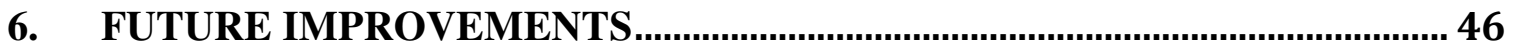

6.1. Multiple sample analysis ............................................................................................. 46

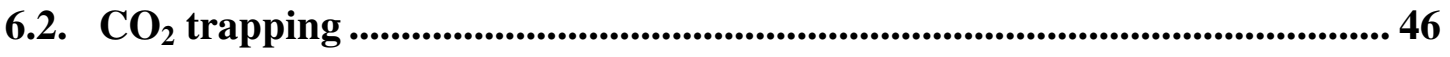

6.3. Parallel sample quantification and storing........................................................... 47

6.4. Automation - control and fault protection ............................................................ 47

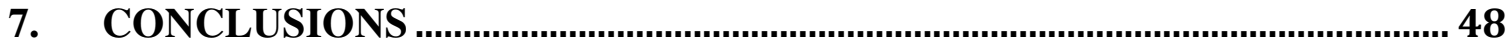




\section{INTRODUCTION AND BACKGROUND}

\section{1. ${ }^{14} \mathrm{C}$ measurements and their importance}

\subsubsection{Historical Background}

Radiocarbon dating is a powerful technique used to determine the age of ancient objects and study the global carbon cycle. The radioactive isotope of carbon, ${ }^{14} \mathrm{C}$, is created when cosmic rays collide with the upper atmosphere to produce secondary neutrons which, in turn, react with the abundant nitrogen-14 isotope to form radiocarbon atoms by eliminating a proton (Eqn 1) (Libby W. , 1961).

$$
n+{ }^{14} N={ }^{1} H+{ }^{14} C
$$

Eqn 1

The radiocarbon is rapidly incorporated into carbon dioxide, transported through the atmosphere and taken up by living creatures and plants through photosynthesis and food chains. When an animal or plant dies it stops replenishing its ${ }^{14} \mathrm{C}$ and the radiocarbon diminishes through radioactive decay with a half-life of about 5730 years (Godwin, 1962). Thus the amount of radiocarbon that remains in an object relative to "modern" carbon and can be used to determine its age.

Radiocarbon dating is used by all branches of science. It was initially developed in the 1950s by Libby and his team to study a variety of fields including nuclear physics, microbiology, and the effects from bomb fallout tests (Libby \& Arnold, 1949). There was also a lot of interest from other disciplines, particularly archeology and anthropology. Over time the radiocarbon dating technique was developed and improved, from the Geiger counter to the accelerator mass spectrometer (AMS), increasing the measurement sensitivity, decreasing the sample size, and allowing for the dating range to be extended to 60,000 years. It is a remarkable technique which has profoundly impacted our understanding of all natural processes in the present and the past. 


\subsubsection{Radiocarbon in climate change and ocean circulation}

Since the start of the Industrial Revolution, roughly forty percent of the anthropogenic $\mathrm{CO}_{2}$ has remained in the atmosphere, increasing $\mathrm{CO}_{2}$ concentration by about 100 partsper-million, and another thirty percent has been absorbed by the oceans (Doney, et al., 2009). The input of $\mathrm{CO}_{2}$ to the atmosphere is contributing to global warming while abiotic absorption by the ocean is resulting in ocean acidification. The rate of both of these effects is predicted to increase substantially over the next century (Doney, et al., 2009). Recent work has indicated that for accurate characterization of these effects the ocean cannot be thought of as a simple global sink for $\mathrm{CO}_{2}$ because of the complexity of the dissolved $\mathrm{CO}_{2}$ system (Sabine, et al., 2004). In order to reliably determine the distribution of the anthropogenic $\mathrm{CO}_{2}$ several processes need to be well understood: the $\mathrm{CO}_{2}$ transfer across the sea surface - air interface, ocean circulation and mixing, and the "biological pump", namely the process of organic carbon, synthesized at the surface, being transferred to the ocean bottom, re-oxidized to inorganic carbon, and circulated back to the surface. The spatial and temporal changes of these processes are not well characterized and geochemical tracers such as radiocarbon can be used to study and quantify them (Peng, Key, \& Östlund, 1997).

The World Ocean Circulation Experiment (WOCE) hydrographic survey program was established to understand the role ocean circulation plays in climate variability, improve the understanding of physical processes in the ocean, and advance ocean models for ocean climate predictions. The program was a tremendous internationally coordinated effort carried out from 1988 until 1998. Its scientific objectives were achieved by advancing ocean observational techniques, both in-situ and satellite-based. One of the techniques used to study the ocean currents was the tracing of components such as radiocarbon, temperature, salinity, nutrients, and freons via thousands of samples collected in various locations from the world's oceans (McNichol, et al., 2000).

The National Ocean Sciences Accelerator Mass Spectrometer (NOSAMS) Facility at the Woods Hole Oceanographic Institution (WHOI) was established in 1989 with the initial 
goal of providing radiocarbon analysis on thousands of water samples for the WOCE Hydrographic Program. NOSAMS carried out stable and radio isotope analysis of the dissolved inorganic carbon (DIC, Eqn 2) of 13,000 samples.

$$
\mathrm{DIC}==\mathrm{CO}_{2}+\mathrm{H}_{2} \mathrm{CO}_{3}+\mathrm{HCO}_{3}^{-}+\mathrm{CO}_{3}^{2-}
$$

Eqn 2

The results provide important constraints to general ocean circulation models and are continuing to show insights into ocean processes (McNichol, et al., 2000). After the WOCE program was completed, NOSAMS continued to process water samples for the Climate Variability and Predictability program (CLIVAR), which was started in 1995 to understand interannual, decadal, and longer periods of climate variability. The facility has processed over 20,000 samples to date, which is the world's largest homogeneous, high precision radiocarbon data set.

\subsection{Current NOSAMS DIC line design}

The seawater samples processed at NOSAMS are currently analyzed using a water stripping line (WSL). The line uses a sparging method to extract the sample DIC as carbon dioxide by acidifying the sample and circulating nitrogen gas through it. The extracted $\mathrm{CO}_{2}$ is then separated cryogenically and stored for further processing (Cohen, et al., 1994). The system provides high yields and produces unfractionated gas that can provide both stable and radiocarbon isotope data. Using Buzzards Bay surface seawater and sodium carbonate standards it was shown that the system strips more than $98 \%$ of the inorganic carbon from each sample. The extracted $\mathrm{CO}_{2}$ gas provides for stable isotope analysis with precision better than $0.03-0.05 \%$, and for radiocarbon analysis with reproducibility better than $3-4 \%$ (McNichol, et al., 2000) (Elder, McNichol, \& A.R., 1998).

The WSL was designed in 1992 specifically to facilitate the WOCE and subsequently, the CLIVAR programs. However, since the completion of WOCE, the NOSAMS facility has broadened its service to include groundwater sample analysis. Thus, the WSL needs improvements to increase its versatility and accommodate a more varied sample pool. For instance, the system was designed to process WOCE seawater samples stored in custom 
collection bottles; e.g. the bottle top and connection to the line were designed to mate appropriately. Unlike seawater, the groundwater samples are provided in varying storage vessels, which are harder to adapt. Other desirable improvements include the capability to process a wide range of DIC concentrations, the shortening of processing time by system optimization, and an improved ability to subsample bottles.

\subsection{New proposed extraction method}

The new water stripping line system will use a different principle to extract the DIC from water samples. Each sample will still be acidified; however, the $\mathrm{CO}_{2}$ extraction will be performed using a micro-porous polymer membrane contractor. Membrane contractors have been used before to study seawater carbonate chemistry, in particular seawater carbon dioxide partial pressure $\left(\mathrm{P}_{\mathrm{CO} 2}\right)$ and seawater DIC (Bandstra, Hales, \& Takahashi, 2006) (Hales, Chipman, \& Takahashi, 2004). In these studies $\mathrm{CO}_{2}$ gas is extracted by the membrane contractor from a continuously flowing seawater stream and measured using a nondispersive infrared detector. The detector provides $\mathrm{P}_{\mathrm{CO} 2}$ and DIC measurements based on whether the seawater stream is acidified. The new water stripping line will utilize the principles used by these studies; however it will also have the capability of trapping and storing the extracted $\mathrm{CO}_{2}$. 


\section{MEMBRANE EXTRACTION TECHNOLOGY}

Membranes have proven to be extremely useful in transporting substances between two media. They can be used to create an active interface that selectively accommodates substance transport at low temperatures, low energy, and without any additives. They can also be easily integrated into a variety of systems. A membrane's properties and performance are determined by the membrane material, and even though ceramic, metal and liquid membranes are gaining more importance, the majority of membranes are made from polymers. This is due to the fact that polymer materials can be used to create a wide variety of barrier structures with different properties (Ulbricht, 2006).

The passive transport of a substance through membranes is facilitated by a chemical potential gradient across the membrane, such as concentration or pressure (Mulder, 1992), and the transport method, mass transfer or permeation, is based on the porosity of the polymer membrane.

\subsection{Membrane types}

There are two kinds of polymer membranes that are used to efficiently extract $\mathrm{CO}_{2}$ : gas separation or non-porous membranes, and gas absorption or micro-porous membranes.

\subsubsection{Gas separation membranes}

Gas separation membranes are non-porous polymer membranes that rely on the selectivity and diffusivity of the gas molecules in the membrane, as well as the partial pressure differential across the membrane to extract the gas of interest. This can be seen in the derivation below.

The gas diffusion through the membrane can be described by Fick's Law (Mulder, 1992):

$$
J=D \frac{\partial c}{\partial x}
$$


where $\mathrm{J}$ is the flux through the membrane, $\mathrm{D}$ is the diffusion coefficient, and $\mathrm{dc} / \mathrm{dx}$ is the gas concentration gradient across the membrane. Assuming a steady state, the equation becomes:

$$
J=D \frac{\left(c_{f}-c_{s}\right)}{l}
$$

where $c_{\mathrm{f}}$ is the gas concentration on the liquid feed side; $c_{\mathrm{s}}$ is the gas concentration on the gas sweep side, and 1 is the membrane thickness. Henry's Law states that at a constant temperature, the gas concentration on the liquid side is directly proportional to the partial pressure of that gas in the gas sweep side:

$$
c=S \cdot p
$$

where $\mathrm{S}$ is the gas solubility coefficient and $\mathrm{p}$ is the gas partial pressure. Substituting for the gas concentration in Eqn 4 gives:

$$
J=D S \frac{\left(p_{f}-p_{s}\right)}{l}
$$

Finally, by substituting the membrane's gas permeability for the product of the solubility $\mathrm{S}$ and diffusivity $\mathrm{D}$, the gas flux is obtained.

$$
J=P \frac{\left(p_{f}-p_{s}\right)}{l}
$$

The gas permeability equation describes the solution-diffusion model for gas transport across non-porous membranes (Wijmans \& Baker, 1995). In this model, the solubility is a thermodynamic factor, which reflects the number of molecules dissolved in the membrane material and the diffusivity is a kinetic parameter which is mainly influenced by the size of the gas molecules under consideration (Baker, 2004).

\subsubsection{Gas absorption membranes}

Gas absorption membranes or membrane contractors are solid, hydrophobic, microporous membranes that act as contacting devices between the gas and liquid flows. They combine the advantages of membrane technology and absorption technology. When us- 
ing membrane contractors, the gas molecules of interest are removed from the liquid stream and transferred through the membrane pores to the gas phase.

In contrast to gas separation membranes, the selectivity is not determined by the membrane material, but instead by the partial pressure of the gas of interest in the sweep stream (Feron \& Jansen, 1992). By Henry's law (Eqn 5), when the partial pressure of the gas above the liquid is reduced, the equilibrium will be shifted and the amount of dissolved gas in the solution will decrease accordingly. For instance, if the gas of interest is $\mathrm{CO}_{2}$, its partial pressure can be constantly decreased on the gas side of the membrane contractor by applying a sweep gas such as pure helium or nitrogen that does not contain any $\mathrm{CO}_{2}$. The partial pressure can also be lowered on the gas side of the membrane by applying vacuum (Liqui-Cel, Membrane Contractors - Introduction to the Technology).

In some cases selective polymers can also be used or added to increase the gas absorption membrane performance. These membranes also provide very rapid extraction compared to gas separation membranes due to their large surface areas, and they were chosen for use in the new extraction system primarily for that reason.

\subsection{Commercial membranes}

Polymer membrane technology became commercially available in the 1980s (Sridha, Smitha, \& Aminabhavi, 2007). Since then, there has been a lot of progress made in improving the chemical and physical properties of polymer membranes as well as optimizing their design to increase performance.

Commercially available gas-liquid membrane contractors offer a unique way to perform $\mathrm{CO}_{2}$ separation for water samples. They are highly flexible in terms of integration and provide rapid extraction of the $\mathrm{CO}_{2}$ gas from the water phase (Gabelman \& Hwang, 1999).

Liqui-Cel is one of the leading companies in membrane contactors manufacturing. LiquiCel membrane contractors can operate over a wide range of flow rates, making them ap- 
plicable in a number of industries, including pharmaceutical, power production, microelectronics, food and beverage, and water treatment. The membrane contractors are made out of thousands of Celgard micro-porous polypropylene hollow fibers combined into an array. The array configuration is such that it optimizes flow capacity and total membrane surface area. The hollow fiber membrane is hydrophobic, which allows the liquid and gas phases to come into contact without dispersing into one another (Liqui-Cel, Design and Operating Procedures).

As previously mentioned, the gas extraction driving force used by the Liqui-Cel contractors is the partial pressure differential between the gas and liquid phases (Fig 1).

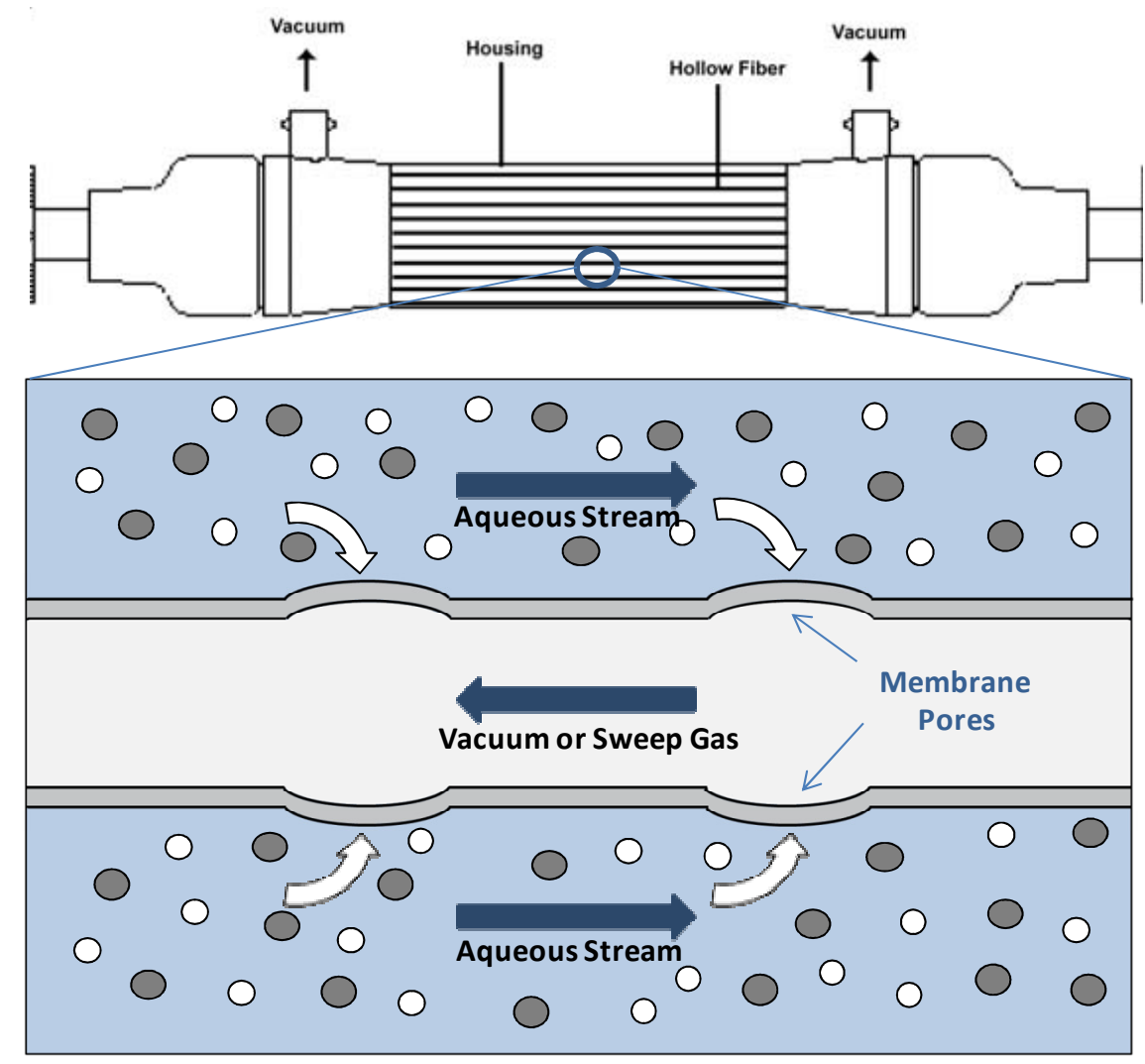

Fig 1. LiquiCel Membrane Contractor, mass transfer between the liquid and gas phases

Liqui-Cel membrane contractors act as an interface between the two phases and facilitate the mass transfer between the phases. This behavior can be modeled with basic theory used to characterize multistage columns. In particular, their performance is evaluated by 
establishing the ratio of inlet-dissolved-gas concentration to outlet-dissolved-gas concentration (Eqn 8) (Liqui-Cel, Membrane Contractors - Introduction to the Technology) .

$$
\frac{c_{o}}{c_{i}}=e^{-k A L / v}
$$

Eqn 8

where $c_{o}$ is the outlet-dissolved-gas concentration, $c_{i}$ is the inlet-dissolved-gas concentration, $\mathrm{k}$ is the mass transfer coefficient, $\mathrm{A}$ is the surface area, $\mathrm{L}$ is the length, and $\mathrm{v}$ is the fluid velocity. The mass transfer coefficient $\mathrm{k}$ indicates how quickly mass travels though a medium, and its reciprocal coefficient indicates the resistance to mass transfer. If the molecule is passing through different media in series, the inverse of the total mass coefficient is the sum of the inverses of the individual mass transfer coefficients. In this case when a gas molecule is being extracted by the membrane contractor it passes through the liquid phase, the membrane, and the gas phase (Eqn 9).

$$
\frac{1}{k_{t}}=\frac{1}{k_{l}}+\frac{1}{k_{m}}+\frac{1}{k_{v}}
$$

where $\mathrm{k}_{\mathrm{l}}$ is the liquid phase mass transfer coefficient, $\mathrm{k}_{\mathrm{m}}$ is the membrane mass transfer coefficient, and $\mathrm{k}_{\mathrm{v}}$ is the vapor phase mass transfer coefficient. Membrane contractors are usually characterized by their performance when extracting oxygen gas. It is well established that oxygen gas molecules encounter the greatest resistance in the liquid phase and that the other two resistances are small or negligible (Yang \& Cussler, 1986). The water mass transfer can be further correlated to the liquid velocity inside the hollow fiber (Eqn 10) using the Sherwood number, which relates convective mass transport to diffusive mass transport (Reed, Semmens, \& Cussler, 1995).

$$
S h=\frac{k d}{D}=1.62\left(\frac{d^{2} v}{L D}\right)^{1 / 3}
$$

where $\mathrm{d}$ is the fiber diameter, $\mathrm{D}$ is oxygen diffusion coefficient, $\mathrm{v}$ is the water velocity, and L is the hollow fiber length. These Sherwood number correlations, in combination with Eqn 8, can be used to show that for a flow through system, the total amount of gas 
removed increases with slower fluid velocities. For a given contractor geometry, this performance can be quantified using percent $\mathrm{O}_{2}$ removal, which is given by $\left(\mathrm{c}_{\mathrm{i}}-\mathrm{c}_{\mathrm{o}}\right) / \mathrm{c}_{\mathrm{i}}$. Percent $\mathrm{O}_{2}$ removed has been determined experimentally for the Liqui-Cel MiniModule membrane contractors by measuring oxygen extracted from the water stream at different water flow rates (Fig 2).

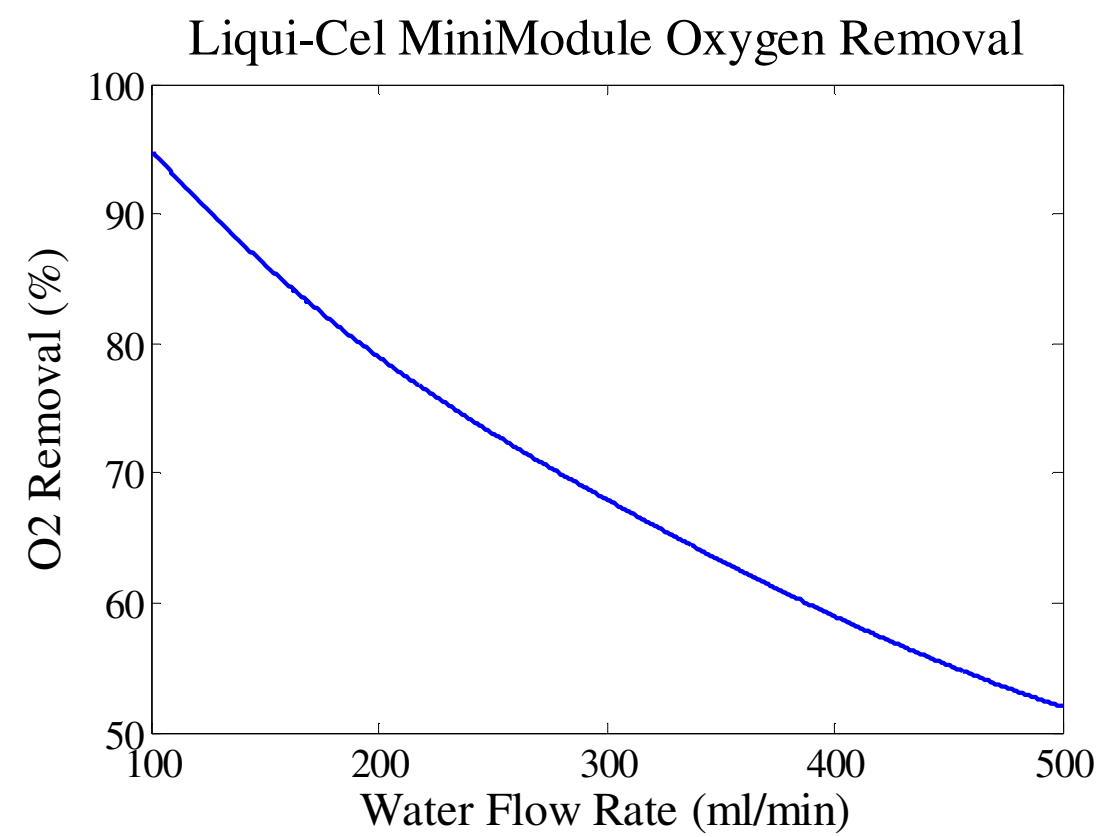

Fig 2. Liqui-Cel MiniModule $\mathrm{O}_{2}$ removal with flow rate (Liqui-Cel, MiniModule Data Sheet)

The data shows that the Liqui-Cel MiniModule membrane contractors exhibit high performance at low flow rates that are easily achievable, and that they would be an appropriate choice for extracting $\mathrm{CO}_{2}$ from aqueous samples. 


\section{SYSTEM OVERVIEW AND DESIGN}

\subsection{System overview and objectives}

The Rapid Extraction of Dissolved Inorganic Carbon System (REDICS) is designed to efficiently extract DIC from seawater and groundwater samples in the form of carbon dioxide gas, and store it for further processing and radiocarbon dating. The NOSAMS facility at WHOI processes thousands of water samples per year which have a wide range of DIC concentrations and are stored in bottles selected by the client. REDICS is designed to accommodate the variability in bottle styles, handle a wide range of DIC concentrations, and strip more than $99 \%$ of the inorganic carbon from each sample. The initial expectation of the system was for it to completely process each sample in less than 20 minutes without isotopically fractionating the $\mathrm{CO}_{2}$. Compared to current methods, this decreases the sample processing time by 15 minutes per sample. REDICS is expected to perform at least as well as the current water stripping line at NOSAMS, by providing $\mathrm{CO}_{2}$ gas that is radiocarbon dated to a similar or better precision and accuracy.

\subsection{Operation principles}

REDICS uses three steps to extract DIC from water samples - sample acidification, to push the DIC equilibrium to $\mathrm{CO}_{2}$, gas extraction, using a hydrophobic polypropylene membrane to selectively retrieve the $\mathrm{CO}_{2}$ gas from the water sample, and cryogenic trapping, which helps trap, quantify, and store the $\mathrm{CO}_{2}$ sample.

\subsubsection{Sample acidification}

In order to extract the DIC from the water sample, all inorganic carbon species - dissolved carbon dioxide $\left(\mathrm{CO}_{2}\right.$, aqueous $)$, carbonic acid $\left(\mathrm{H}_{2} \mathrm{CO}_{3}\right)$, bicarbonate anions $\left(\mathrm{HCO}_{3}{ }^{-}\right)$, and carbonate anions $\left(\mathrm{CO}_{3}{ }^{2-}\right)$ - are converted to $\mathrm{CO}_{2}$ gas by acidifying it with a strong acid (Eqn 11).

$$
\begin{aligned}
& \mathrm{CO}_{2, \text { gas }} \leftrightarrow \mathrm{CO}_{2, \text { aqueous }}+\mathrm{H}_{2} \mathrm{O} \leftrightarrow \mathrm{H}_{2} \mathrm{CO}_{3} \leftrightarrow \mathrm{H}^{+}+\mathrm{HCO}_{3}^{-} \leftrightarrow \mathrm{H}^{+}+\mathrm{CO}_{3}^{2-} \text { Eqn } 11
\end{aligned}
$$

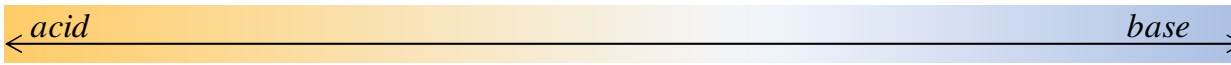




\subsubsection{Gas extraction}

After acidification, REDICS uses a LiquiCel 1x5.5 MiniModule membrane contractor to extract the $\mathrm{CO}_{2}$ gas from the sample. This membrane contractor consists of 50 microporous polypropylene hollow fibers combined into an array. This geometry gives it a large surface area which, in turn, increases the gas flow capacity across the membrane (Fig 3).

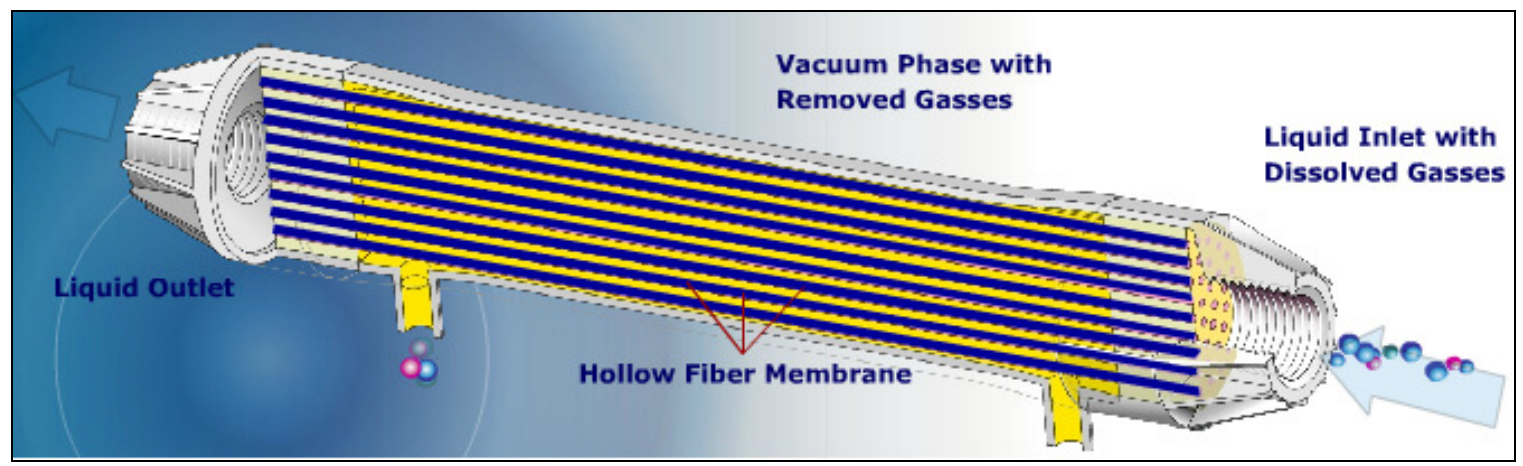

Fig 3. LiquiCel 1x5.5 MiniModule design (Liqui-Cel, Design and Operating Procedures)

The liquid sample is passed though the fibers while the sweep gas flows on the outside. The polypropylene fibers are hydrophobic and create a gas/liquid interface that does not allow easy aqueous penetration through the fiber pores. The pressure required to force liquid through the pores can be calculated by the Young-Laplace equation (Eqn 12) modified for use with hydrophobic membranes (Kim, 1987).

$$
P=-2 \sigma \cos \theta / r
$$

where $\mathrm{P}$ is the breakthrough pressure across the membrane, $\theta$ is the contact angle, $\sigma$ is the surface tension of the water, and $\mathrm{r}$ is the radius of the fiber pores. Given the polypropylene fiber pore radius of 0.05 microns, water surface tension of $0.075 \mathrm{~N} / \mathrm{m}^{2}$, and a contact angle of $108^{\circ}$ for water on polypropylene, the breakthrough pressure of the membrane is calculated to be $135 \mathrm{psi}$. This pressure is sufficiently high to prevent water molecules from entering the gas phase and thus prevents the two phases from dispersing into one another. 
Since REDICS uses a sweep gas that constantly removes $\mathrm{CO}_{2}$ from the gas phase, there is a continuous mass transfer of $\mathrm{CO}_{2}$ from the liquid side to the gas side. The sweep gas, in this case helium, liberates the liquid phase of all dissolved gases that experience partial pressure differential across the membrane, e.g. water vapor, oxygen, and nitrogen.

\subsubsection{Cryogenic trapping}

REDICS uses cryogenic trapping to extract the $\mathrm{CO}_{2}$ from the carrier gas stream. The system uses two types of traps in series. The first type is an isopropanol/dry ice slush trap at $195^{\circ} \mathrm{K}$ which is used to eliminate water vapor from the sweep gas stream. The second type is a liquid nitrogen $\left(\mathrm{LN}_{2}\right)$ trap at $83^{\circ} \mathrm{K}$, which is used to collect and transfer $\mathrm{CO}_{2}$. The vapor pressure chart below verifies that at low pressures the isopropanol/dry ice slush trap will efficiently extract the water vapor from the carrier stream, and the liquid nitrogen trap will extract the $\mathrm{CO}_{2}$ and potentially hydrogen sulfide $\left(\mathrm{H}_{2} \mathrm{~S}\right)$ and nitrous oxide $\left(\mathrm{N}_{2} \mathrm{O}\right)$ if they are present in the sample (Fig 4). (Lide, 1995)

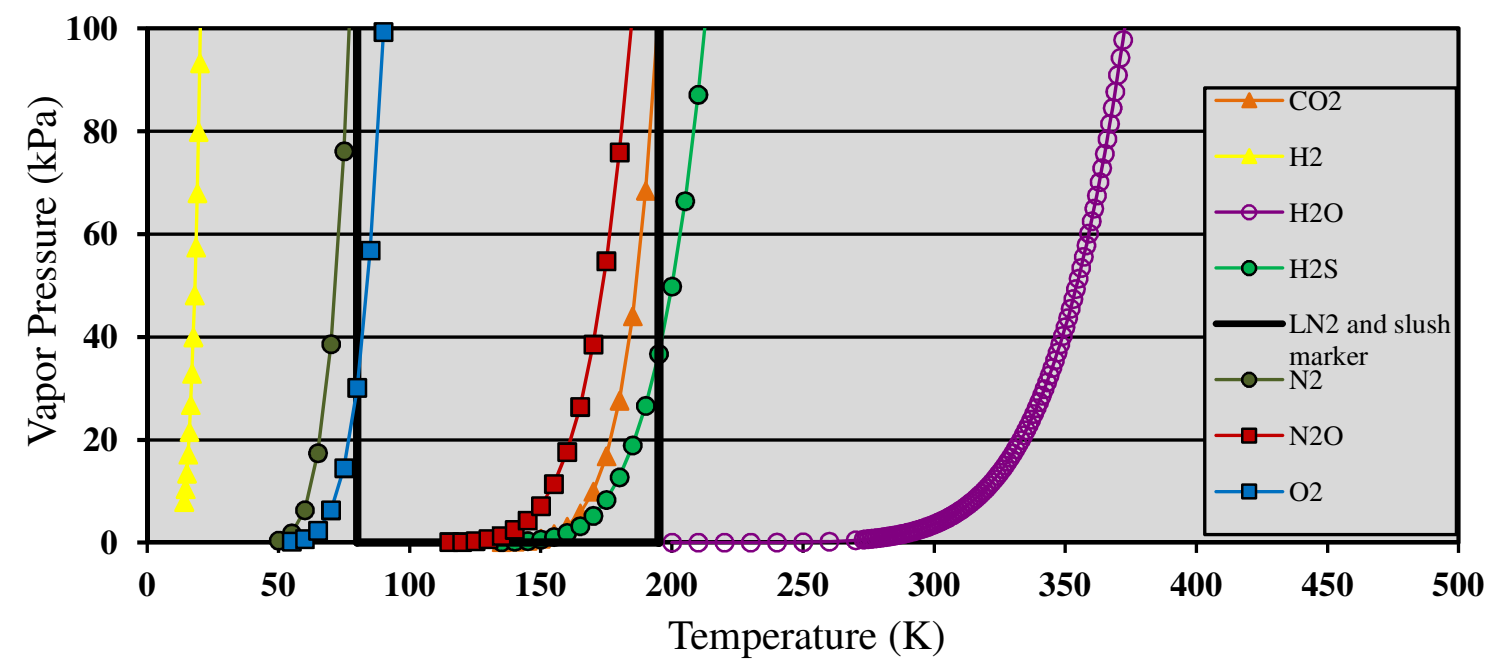

Fig 4. Vapor pressure diagram of gases expected in seawater and groundwater samples (graph based on compilation by S. Beaupre)

\subsection{System component description and operation}

REDICS consists of two major subsystems - one for sample introduction, acidification, and $\mathrm{CO}_{2}$ extraction (IAE), and one for $\mathrm{CO}_{2}$ trapping, quantification and storing (TQS). 


\subsubsection{Sample introduction, acidification, and $\mathrm{CO}_{2}$ extraction subsystem}

This part of the system efficiently introduces the water sample to the system, acidifies it in a closed loop, and extracts the freed $\mathrm{CO}_{2}$ via the membrane contractor (Fig 5).

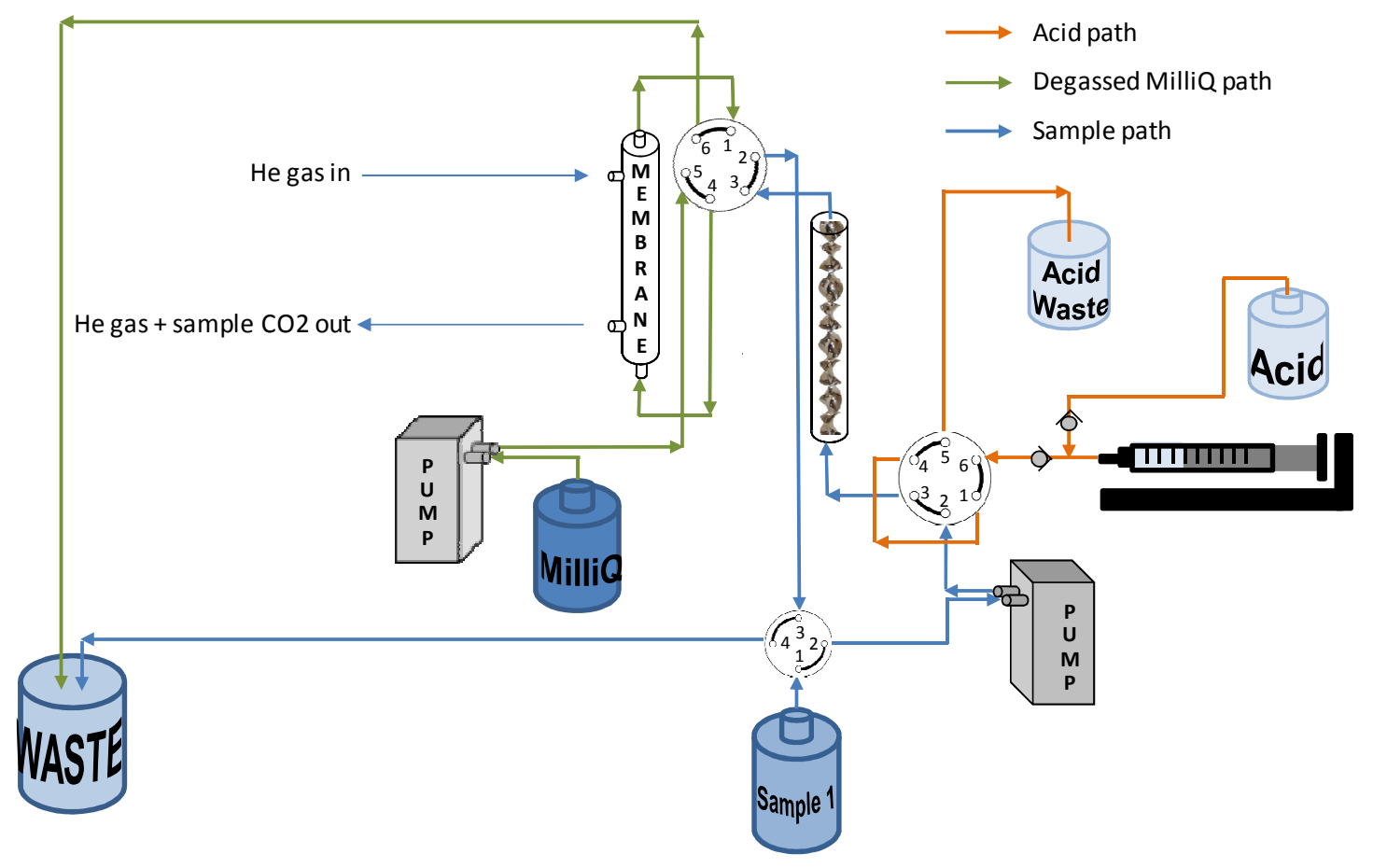

Fig 5. Sample introduction, acidification, and $\mathrm{CO}_{2}$ extraction subsystem

- Sample introduction

The sample of interest is initially placed in a nitrogen gas glove bag in order to exchange the bottle glass stopper with a rubber stopper without exposing the sample to air. The rubber stopper has two channels - one connects to the system's sample introduction line, and the other connects to a helium gas line, which ensures that the sample is displaced with $\mathrm{CO}_{2}$ free air when it is extracted from the bottle (Fig 6). 


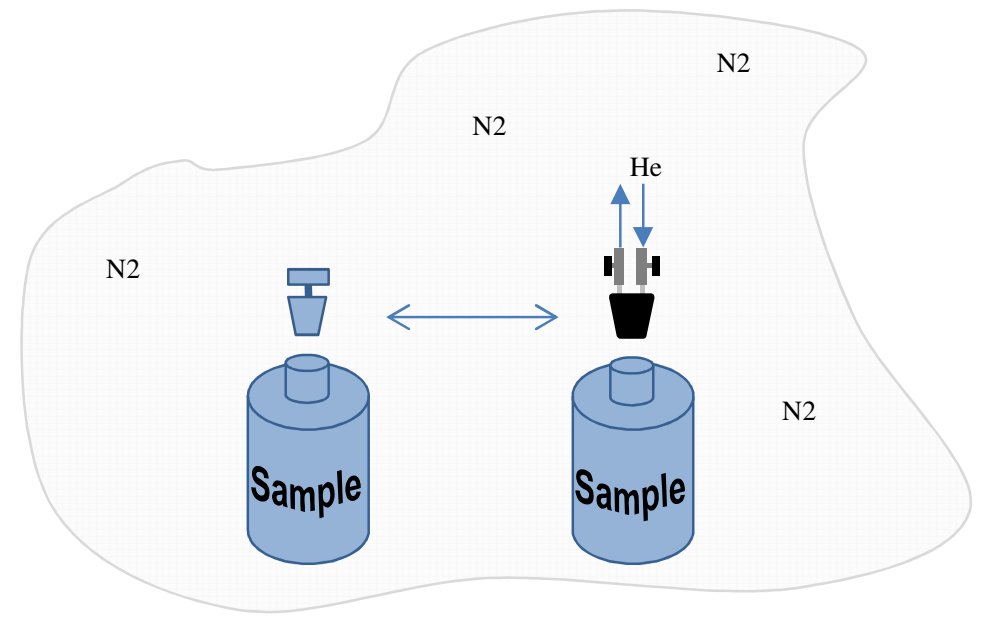

Fig 6. Sample stopper exchange.

Once the stopper has been exchanged, the sample is removed from the nitrogen glove bag and the stopper is connected to the system's sample introduction line.

The sample is introduced to the system using a KNF NF10 TVDC micro diaphragm liquid pump which pulls the sample from the sample bottle at a flow rate of 100 $\mathrm{ml} / \mathrm{min}$. The sample line is pumped through several components - a Valco Cheminert four port valve, the KNF pump, a Cheminert six port valve, a static mixer reservoir, a Valco Cheminert six port valve, and back to the Valco Cheminert four port valve.

REDICS is designed to analyze a small portion of each water sample - either $46 \mathrm{ml}$ or $92 \mathrm{ml}$. Since samples are between $250 \mathrm{ml}-500 \mathrm{ml}$ in volume, some of the sample is used to purge the system prior to sample analysis. This is accomplished using the four port valve in its initial position which allows the sample to flow freely to waste. When the valve is switched later on, it isolates the part of the sample which is to be analyzed in a closed loop. The two six port valves are used to introduce the acid to the sample and incorporate the membrane contractor into the sample closed loop. The static mixer reservoir is where most of the sample is contained, and it allows for efficient sample acidification by ensuring thorough mixing of the acid with the sample. 
The IAE subsystem of REDICS is plumbed entirely with tubing and connections made of polyether ether ketone (PEEK) due to the low $\mathrm{CO}_{2}$ permeability of the PEEK polymer (De Candia \& Vittoria, 1994).

- Sample acidification

REDICS uses phosphoric acid to acidify the sample. The phosphoric acid is introduced using a syringe pump connected to one of the six port valves. The syringe fills a loop of peek tubing with acid, the length of which determines the amount of acid that will be added to the sample. In the six port valve's initial position, the acid loop is isolated from the sample line. When the valve is switched the loop becomes a part of the sample line. Thus the acid addition does not add volume which would increase the sample loop pressure (Fig 7).

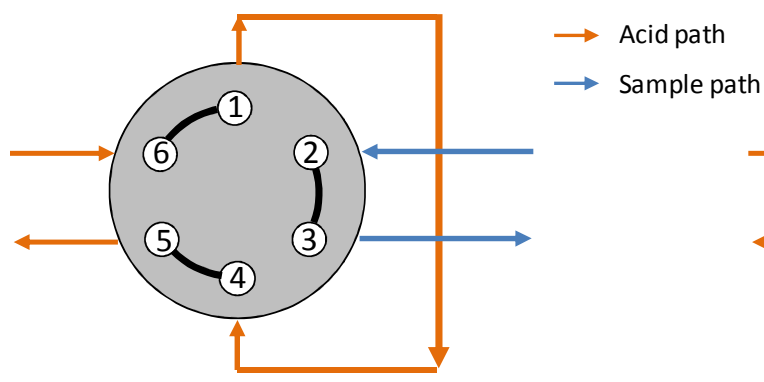

Acid Loop Loaded

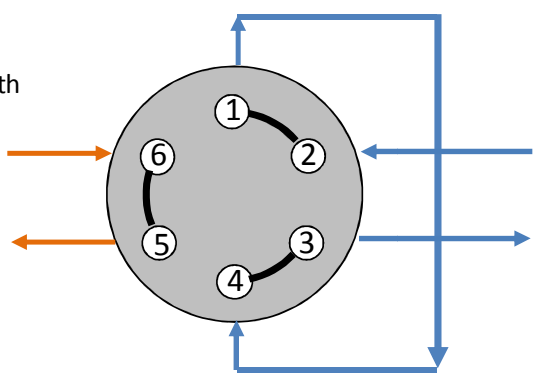

Acid Loop Added to Sample

Fig 7. Valco six port valve acid addition.

Once the acid is introduced to the sample loop, the sample and acid pass through the static mixer which efficiently homogenizes the solution. The static mixer is specifically designed to accommodate efficient mixing of the sample, the acid, and degassed MilliQ water. It consists of 16 polypropylene helical mixer elements enclosed in a cylindrical PEEK housing (Fig 8). It also acts as a sample reservoir, since most of the analyzed sample is contained within the mixer volume.

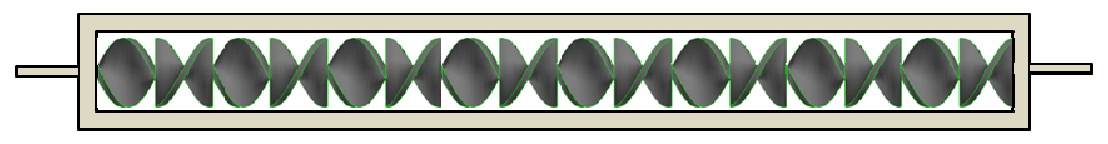

Fig 8. Static Mixer 


\section{- $\mathrm{CO}_{2}$ extraction}

The membrane contractor is connected to a six port valve and is flushed with degassed MilliQ water while the sample is being introduced and acidified. The membrane contractor is a part of a valve loop which is added to the sample loop after acidification (Fig 9).

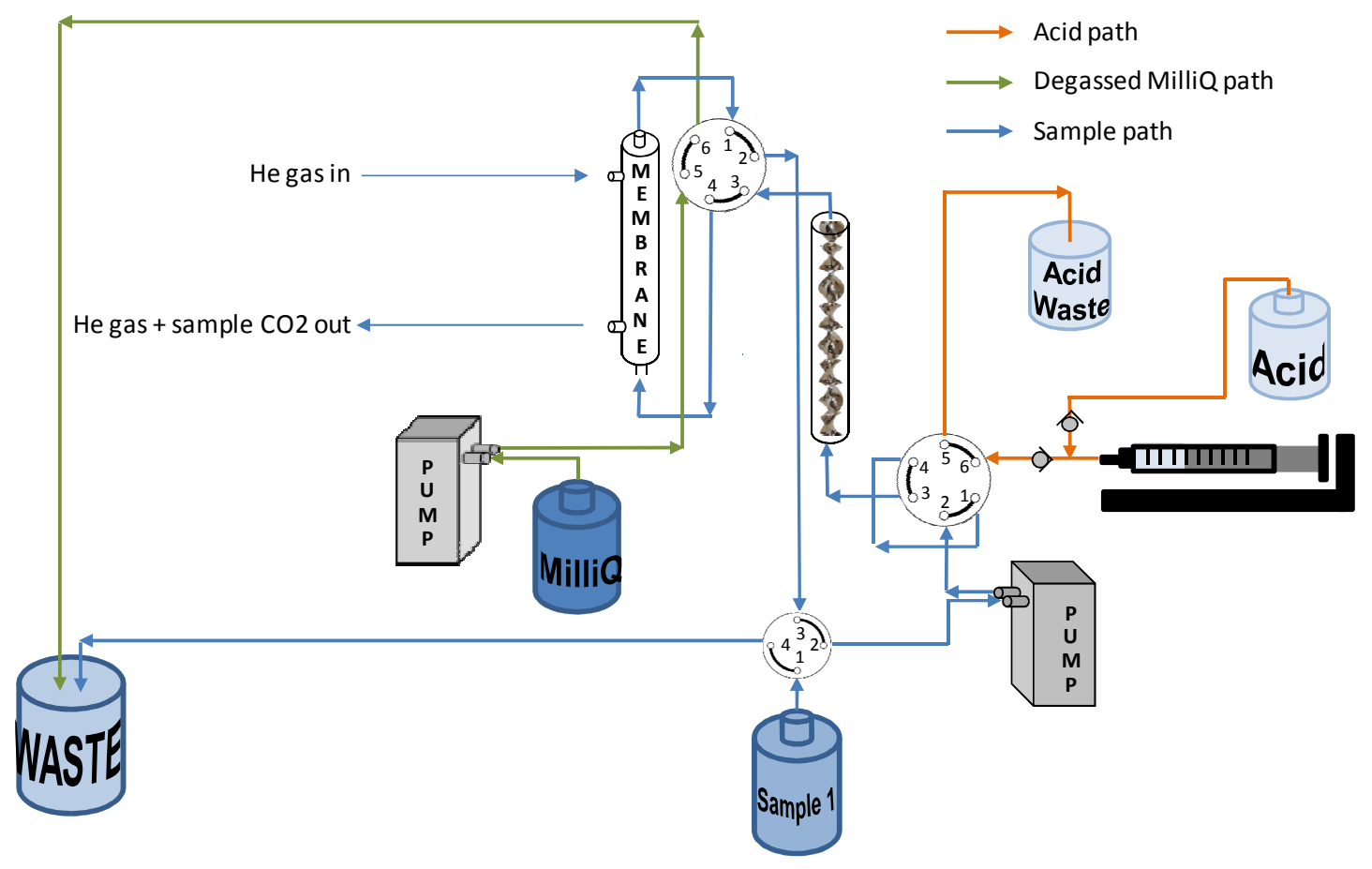

Fig 9. Sample path after membrane and acid addition.

Since the contractor contains only degassed water, no additional $\mathrm{CO}_{2}$ is introduced, which was verified by processing a blank water sample through the system. The contractor volume is added to the acidified sample loop, and the final solution continues being circulated until all the $\mathrm{CO}_{2}$ is extracted through the contractor.

REDICS uses ultra pure helium as a sweep gas, and it is passed through an ascarite trap to ensure it is fully free of $\mathrm{CO}_{2}$. It is passed through the membrane contractor at a flow rate of $1 \mathrm{~L} / \mathrm{min}$ and a pressure of 10 psi. Once the $\mathrm{CO}_{2}$ enters the gas stream, it is 
passed through a Sable Systems CA-2A IR $\mathrm{CO}_{2}$ analyzer for rough quantification and further processing.

\subsection{2. $\mathrm{CO}_{2}$ trapping, quantification and storing subsystem}

The TQS subsystem is used to quantify and trap the extracted $\mathrm{CO}_{2}$ (Fig 10). The gas path is constructed from borosilicate glass tubing connected with Swagelok ultra-torr fittings.

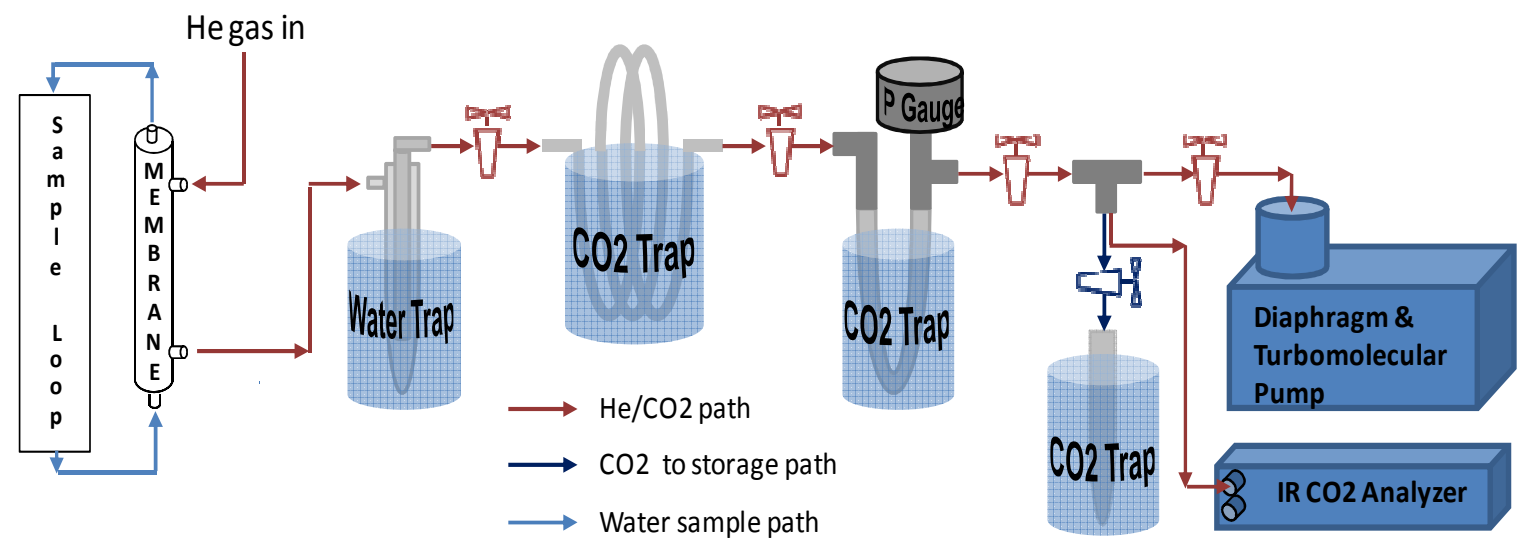

Fig 10. $\mathrm{CO}_{2}$ quantification and storing subsytem

\section{- Water trap}

The $\mathrm{CO}_{2}$ is extracted from the sample by the membrane contractor in less than 4 minutes. The sweep gas stream is stripped of water vapor when it passes through the isopropanol/dry ice water trap.

- Sable Systems CA-2A IR $\mathrm{CO}_{2}$ analyzer

The $\mathrm{CO}_{2}$ IR analyzer can be integrated at two different locations in the system and was used to assess the performance of both subsystems throughout the validation process. When connected right after the water trap, the analyzer is used to provide a rough quantification of the extracted $\mathrm{CO}_{2}$ amount as well as to indicate the completion of the extraction. This set-up was used for validating the IAE subsystem. When connected at the end of the TQS subsystem it is used to ensure that all of the extracted $\mathrm{CO}_{2}$ is fully captured by the $\mathrm{CO}_{2}$ traps discussed below. The IR analyzer is calibrated 
prior to each sample analysis using ultra pure helium gas and a $500 \mathrm{ppm} \mathrm{CO}_{2} / \mathrm{He}$ standard.

- Liquid nitrogen traps and quantification volume

After exiting the water trap the sweep gas is passed through two $\mathrm{LN}_{2}$ traps which strip the $\mathrm{CO}_{2}$ from the stream. The traps are made out of borosilicate glass. The first one is a multi-loop trap filled with glass beads. The second one is a U-shape that is filled with glass beads on the bottom and two glass rods in each vertical section. The purpose of the glass beads and rods in the traps is to increase surface area which helps guarantee complete extraction of $\mathrm{CO}_{2}$ from the helium stream (Fig 11).

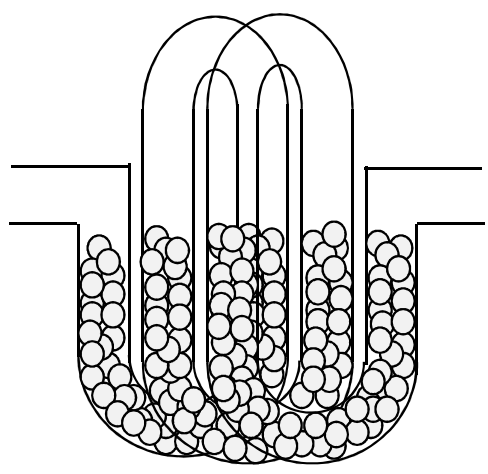

First $\mathrm{LN}_{2}$ Trap

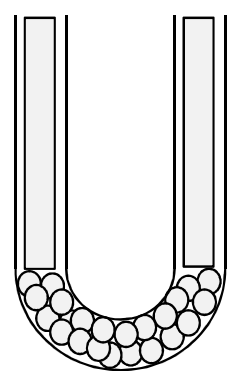

Second $\mathrm{LN}_{2}$ Trap

Fig 11. $\mathrm{LN}_{2}$ traps

Initially, the system used only the second $\mathrm{LN}_{2}$ trap for the $\mathrm{CO}_{2}$ cryogenic extraction from the sweep gas. However, this configuration proved insufficient for the high sweep flow rate of $1 \mathrm{~L} / \mathrm{min}$ that the membrane contractor requires, and $10 \%$ of the sample $\mathrm{CO}_{2}$ was lost. The first trap was then added to ensure complete trapping.

Once the $\mathrm{CO}_{2}$ is captured in both traps, the traps are isolated from the rest of the system using glass valves. The $\mathrm{CO}_{2}$ analyzer, which is connected at the end of the system, is disconnected and a finger flask for storing the extracted $\mathrm{CO}_{2}$ is attached to the port. An Alcatel Diaphragm \& Turbomolecular Pump is used to pump away the helium gas and any other remaining incondesible gases that might have been in the car- 
rier flow. It also evacuates the finger flask. Once evacuated, the traps are again isolated, and the $\mathrm{CO}_{2}$ from the first trap is cryogenically transferred to the second trap by removing the $\mathrm{LN}_{2}$ from the first trap and warming it to room temperature.

After the $\mathrm{CO}_{2}$ has been cryogenically transferred to the trap, it is completely isolated on either side via glass valves and expanded for quantification by an MKS Baratron capacitance manometer, which is connected to the trap via an ultra-torr fitting. The volume of the trap has been pre-calibrated and is used together with temperature and pressure readings to quantify the amount of $\mathrm{CO}_{2}$ extracted from the water sample using the ideal gas law (Eqn 13).

$$
n=P V / R T
$$

Eqn 13

where $\mathrm{P}$ is the pressure, $\mathrm{V}$ is the volume, $\mathrm{T}$ is the temperature, and $\mathrm{R}$ is the universal gas constant.

Once the sample has been quantified it is cryogenically transferred via another $\mathrm{LN}_{2}$ trap to the storage finger flask. The flask can be isolated from the system with a glass valve. Once the sample is transferred, the valve is closed, the flask is completely disconnected from the system, and the sample is ready for further processing. 


\section{CALIBRATION AND VALIDATION PROCEDURES}

\subsection{Membrane performance}

The REDICS IAE subsystem and its membrane performance were tested using sodium carbonate $\left(\mathrm{Na}_{2} \mathrm{CO}_{3}\right)$ standards. The IR $\mathrm{CO}_{2}$ analyzer was used to roughly quantify the amount of extracted $\mathrm{CO}_{2}$ and the extraction time. For that purpose the analyzer was connected to the outlet of the membrane contractor. The $\mathrm{CO}_{2}$ was not collected past the analyzer for this test. The standards used for the quantification contained $\mathrm{CO}_{2}$ concentrations of $0.50 \mathrm{mM}, 1.07 \mathrm{mM}, 2.00 \mathrm{mM}$, and $4.01 \mathrm{mM}$. Given that the total sample volume of the system is $45.8 \mathrm{ml}$, the amount of $\mathrm{CO}_{2}$ in each standard was calculated to be -23.2 $\mu$ mols, $46.8 \mu$ mols, $92.1 \mu$ mols, and $184.6 \mu$ mols respectively. The flow rate of the sweep gas through the membrane contractor was measured using a flow meter, and the value was used to convert the analyzer's output of ppm to amount of $\mathrm{CO}_{2}$ extracted in $\mu$ mols. It should be noted that the constant carrier flow rate of $1 \mathrm{~L} / \mathrm{min}$ measured prior to the extraction was assumed to be equal to the flow rate through the analyzer for the duration of each test (i.e. the flow rate was not adjusted for variation due to additional $\mathrm{CO}_{2}$ in the sweep gas stream). Thus the results of this test were used to obtain only a rough quantification of total $\mathrm{CO}_{2}$ removed. The test data also provides some insight into the mixing efficiency of the static mixer (Fig 12).
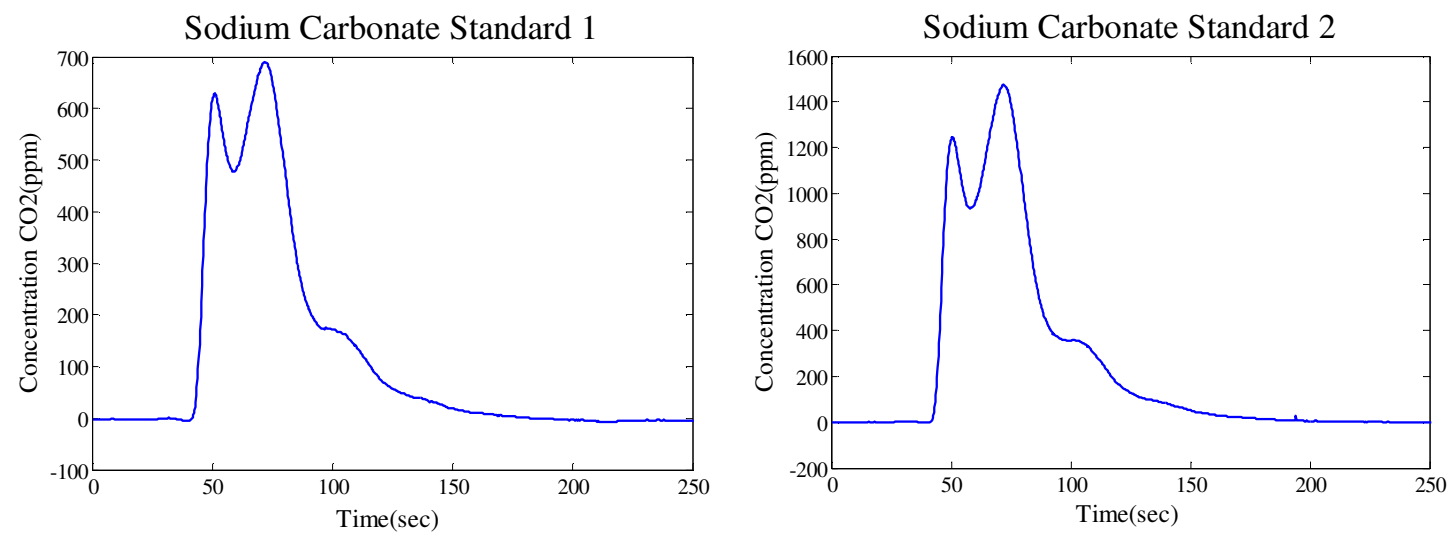

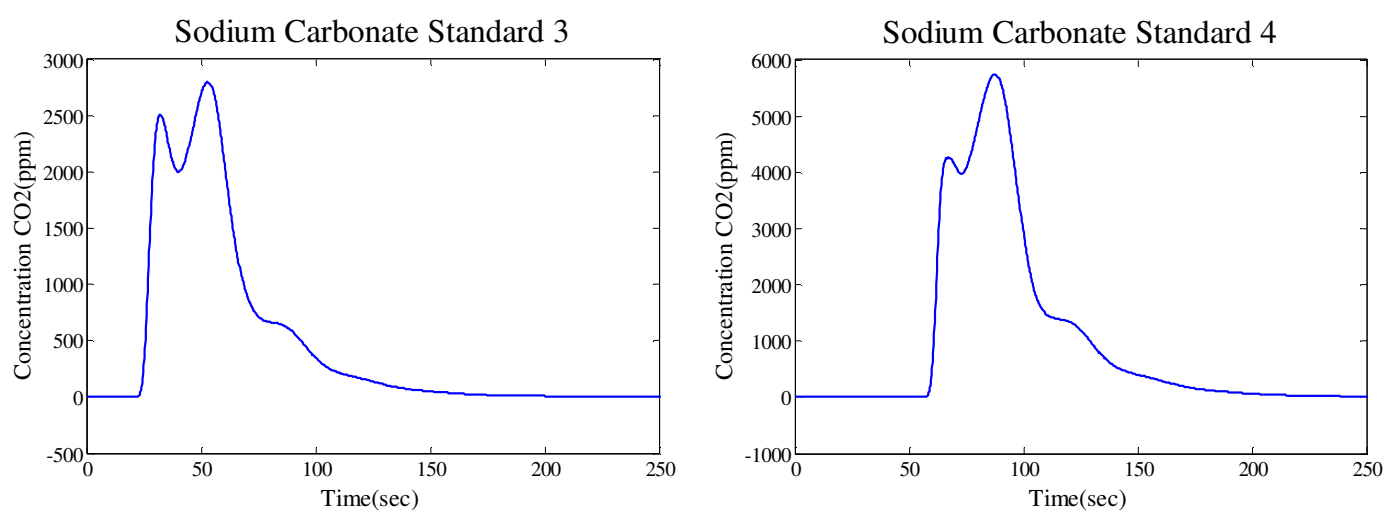

Fig 12. Sodium Carbonate Standards

The unusual peak shape, which is extremely reproducible, is due to the time it takes for the sample to be homogenized within the IAE subsystem. The peak's "valley" occurs when the degassed water added by the membrane contractor loop passes by the membrane before it is fully mixed with the rest of the sample. The data also shows that each sample is fully extracted within 4 minutes, which is a significant improvement over the 35 min extraction time for the current NOSAMS WSL.

In order to convert the ppm data from the $\mathrm{CO}_{2}$ IR analyzer to $\mu$ mols of $\mathrm{CO}_{2}$ extracted, the total peak area is calculated for each sample using Trapezoidal integration. The area, along with an average sweep gas flow rate, is then used to calculate the total amount of $\mathrm{CO}_{2}$.

$$
\mathrm{CO}_{2}(\mathrm{~mol})=(\text { Area }(\mathrm{ppm} \cdot \mathrm{sec}))\left(\frac{1 \mathrm{~min}}{60 \mathrm{sec}}\right)\left(\text { FlowRate } \frac{\mathrm{ml}}{\mathrm{min}}\right)\left(\frac{1 \mathrm{l}}{1000 \mathrm{ml}}\right)\left(\frac{1 \mathrm{~mol}}{24.1 \mathrm{l}}(\mathrm{STP})\right) \quad \text { Eqn } 14
$$

This calculation resulted in the following amounts for each standard: $20.5 \mu$ mols, 43.1 $\mu$ mols, $84.7 \mu \mathrm{mols}$, and $172.4 \mu \mathrm{mols}$. The small error in the measurements is likely due to the use of an average flow rate and also not accounting for pressure and temperature variations in the calculations (Fig 13). 


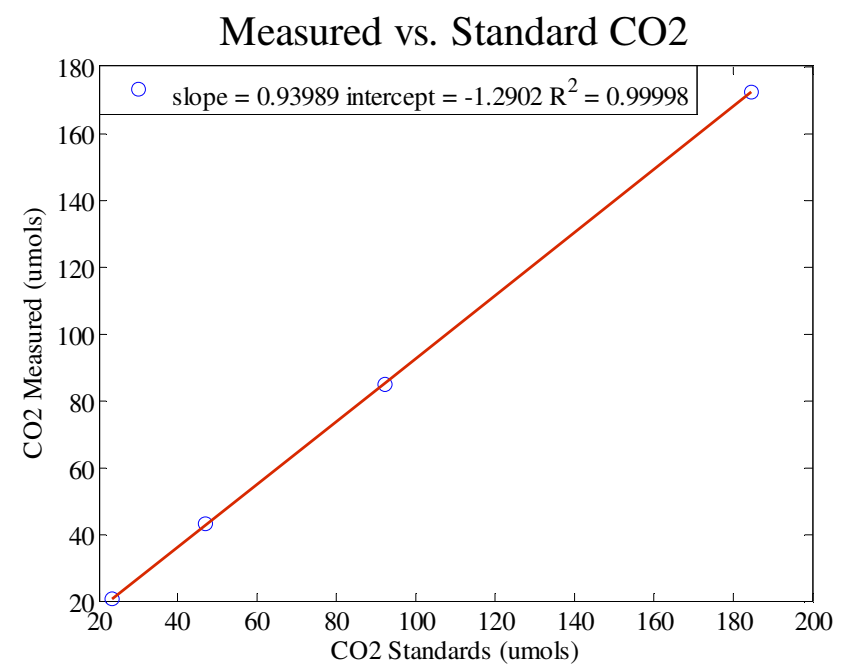

Fig 13. CO2 measured by the IAE subsystem vs. standards $\mathrm{CO} 2$ values

\section{2. $\mathrm{CO}_{2}$ trap volume calibration}

For every sample run, once the $\mathrm{CO}_{2}$ is cryogenically transferred to the second $\mathrm{LN}_{2}$ trap, it is expanded for quantification using the ideal gas law (Eqn 13). The only unknown in the equation was the trap's volume, and it needed to be determined. The calibration was done using a finger flask of known volume filled with an unknown amount of $\mathrm{CO}_{2}$ gas (Fig 14).

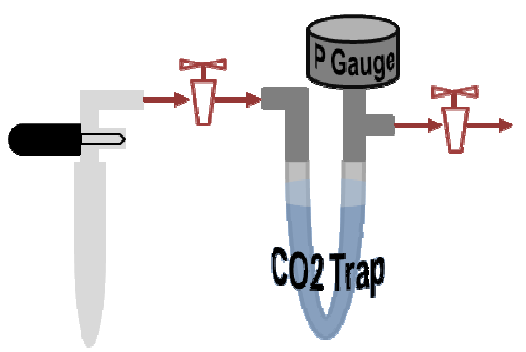

Fig 14. Finger flask of known volume attached to second $\mathrm{LN}_{2}$ trap for volume quantification.

The finger flask was attached to the trap and, while still closed, the trap and all the lines were evacuated using the vacuum pump. The finger flask and trap were then isolated and the $\mathrm{CO}_{2}$ gas was expanded in the entire volume. The Baratron capacitance manometer was used to determine the pressure. Then the flask was closed with the trapped $\mathrm{CO}_{2}$ gas filling its volume, and the rest of the $\mathrm{CO} 2$ was pumped away. The system was isolated again, and this time the $\mathrm{CO}_{2}$ from the finger flask was cryogenically transferred to the 
trap. Then the trap was isolated, and the gas was expanded. This allowed for a second pressure reading to be obtained. Since the temperature did not vary throughout this procedure, the volume of the second $\mathrm{LN}_{2}$ trap is determined using the ideal gas law (Eqn 13).

$$
P_{\text {trap }} V_{\text {trap }}=P_{\text {flask }} V_{\text {flask }}
$$

Eqn 15

The volume of the second $\mathrm{LN}_{2}$ trap was determined to be $19.44 \pm 0.08 \mathrm{ml}$.

\section{3. $\mathrm{CO}_{2}$ trap performance validation}

As previously mentioned, initially only one $\mathrm{LN}_{2}$ trap was used to extract the $\mathrm{CO}_{2}$ from the helium gas stream. The IR $\mathrm{CO}_{2}$ analyzer was connected past the trap to ensure that no part of the sample was lost. It was determined that for the high sweep flow rate of 1 $\mathrm{L} / \mathrm{min}$, which is based on membrane contractor specifications, approximately $10 \%$ of the sample $\mathrm{CO}_{2}$ was lost. As a result, a second multi-loop $\mathrm{LN}_{2}$ trap was added to ensure that more than $99 \%$ of the sample $\mathrm{CO}_{2}$ was trapped. The IR $\mathrm{CO}_{2}$ analyzer was used as an extraction verification tool for every sample analysis.

\subsection{Full system validation procedure}

The entire system's performance was tested using seawater standards collected in the Atlantic Ocean in 2010 at depths $470 \mathrm{~m}$ and $4000 \mathrm{~m}$ depth (latitude $7.9928^{\circ}$, longitude $51.5010^{\circ}$ ). Several standards were processed with both the NOSAMS WSL and REDICS, and the collected $\mathrm{CO}_{2}$ from the systems was analyzed for stable isotopes using either a VG Prism or VG Optima isotope ratio mass spectrometer. In total, three samples of each depth were processed on the WSL, and thirty-one (13 shallow and 18 deep) were processed on REDICS. Further radiocarbon analysis was performed on the three deep samples processed by WSL and on four of the deep water samples processed on REDICS. It is important to note that an entire bottle of seawater is used when the sample is processed on the NOSAMS stripping line. In contrast, the 31 samples processed on REDICS came from 11 sample bottles. The stable and radiocarbon results from both extracting systems were compared in order to establish any discrepancies and to evaluate the performance of REDICS. 
During the validation and testing of the system it was determined by the initial results that the samples were fractionating and that certain system components needed to be improved. One major modification was made to the TQS subsystem and the overall system performance was improved. This modification and results are discussed in the results chapter.

\subsubsection{Seawater $\delta^{13} \mathrm{C}$ measurements}

The stable carbon isotope is reported as $\delta^{13} \mathrm{C}$, which is a measure of the ${ }^{13} \mathrm{C} /{ }^{12} \mathrm{C}$ ratio in the sample referenced to the ratio of a standard material (Eqn 16).

$$
\delta^{13} C=\left[\frac{{ }^{13} R_{\text {sample }}}{{ }^{13} R_{\text {standard }}}-1\right] \times 1000 \quad \text { Eqn } 16
$$

where ${ }^{13} \mathrm{R}={ }^{13} \mathrm{C} /{ }^{12} \mathrm{C}$. The standard is obtained from a Cretaceous marine fossil, Belemnitella Americana, found in the Pee Dee Formation in South Carolina, and thus it is known as the Pee Dee Belemnitella (PDB) standard. The material has an unusually high ${ }^{13} \mathrm{C} /{ }^{12} \mathrm{C}$ ratio of $0.0112372 \%$ and it is assigned a $\delta^{13} \mathrm{C}$ value of zero for convenience, thus giving most other natural samples a negative $\delta^{13} \mathrm{C}$ value (Kenneth, 1982). The material from original sample has been used up; however a new standard has been calibrated to the original fossil in a laboratory in Vienna, known as VPDB. Stable carbon isotope values are still recorded relative to PDB; however the VPDB term is used to indicate that the values are normalized to the new standard. In general the DIC in the oceans has a null or slightly enriched $\delta^{13} \mathrm{C}$. In the surface water the organic matter created by plankton photosynthesis incorporates ${ }^{12} \mathrm{C}$ in a higher proportion than ${ }^{13} \mathrm{C}$, so the ${ }^{13} \mathrm{C}$ remains relatively elevated. At depth the water is relatively depleted in ${ }^{13} \mathrm{C}$ compared to the surface because large amounts of ${ }^{12} \mathrm{C}$-enriched organic matter gets transported from above, and remineralized. As a result the ${ }^{13} \mathrm{C}$ value in the deep ocean tends to be null, or just slightly enriched, while the ${ }^{13} \mathrm{C}$ value at the surface tends to be significantly enriched. 


\subsubsection{Seawater radiocarbon measurements}

Radiocarbon is also measured as an isotope ratio, either to ${ }^{13} \mathrm{C}$ or ${ }^{12} \mathrm{C}$. When radiocarbon is processed in nature, just like ${ }^{13} \mathrm{C}$, it fractionates. Therefore the measured ratios not only reflect the radiocarbon decay, but the fractionation as well. To mitigate this issue, the ratios are corrected by normalizing their ${ }^{13} \mathrm{C}$ values to $-25 \%$, the value of the 1890 wood absolute radiocarbon standard, chosen because it was growing prior to the fossil fuel effects of the industrial revolution. The normalized values allow for a comparison of radiocarbon values primarily based on radiocarbon decay (Eqn 17, Eqn 18) (McNichol \& Aluwihare, 2007) or mixing of reservoirs.

$$
\begin{gathered}
R_{S n}=R_{S}\left[\frac{1+0.001 \times(-25)}{1+0.001 \times \delta^{13} C_{S}}\right]^{2} \\
R_{S n}=R_{S}\left[\frac{1+0.001 \times(-25)}{1+0.001 \times \delta^{13} C_{S}}\right]
\end{gathered}
$$

where $R_{\mathrm{sn}}$ is the normalized sample ${ }^{13} \mathrm{C} /{ }^{12} \mathrm{C}$ ratio, and $\mathrm{R}_{\mathrm{s}}$ is the measured ${ }^{13} \mathrm{C} /{ }^{12} \mathrm{C}$ ratio. The first equation is used by labs, such as NOSAMS, which measure ${ }^{14} \mathrm{C} /{ }^{12} \mathrm{C}$, and the second ratio is used by labs which measure ${ }^{14} \mathrm{C} /{ }^{13} \mathrm{C}$.

Radiocarbon values are reported in fraction modern (fm) or $\Delta^{14} \mathrm{C}$ (Eqn 19, Eqn 20).

$$
\begin{aligned}
& f m=\frac{R_{s n}}{R_{m}} \\
& \Delta{ }^{14} C=1000 \times\left[f m \times e^{-\lambda(y-1950)}-1\right]
\end{aligned}
$$

where $\mathrm{y}$ is the year the sample was collected, and $\lambda=1.201 \mathrm{e}-4$ is the decay constant for ${ }^{14} \mathrm{C}$ based on its half-life. As previously mentioned the $\mathrm{CO}_{2}$ from four of the deep water samples processed on REDICS was converted to graphite and analyzed on the Tandetron accelerator mass spectrometer at NOSAMS to obtain fm values. The results were compared to the radiocarbon data from the NOSAMS WSL and are discussed in the results chapter. 


\section{RESULTS}

\subsection{Data analysis}

The $\delta^{13} \mathrm{C}$ and fm measurements of the samples processed by the NOSAMS water stripping line and by REDICS are summarized in the tables and figures below. The results are discussed in terms of the development of the best system as well as evaluated for agreement with results from NOSAMS standard system. Stable isotope values should be precise to $0.03-0.05 \%$ and radiocarbon values to $4-5 \%$.

Table 1. Stable and radiocarbon isotope data for shallow and deep Atlantic samples processed by WSL

\begin{tabular}{|c|c|c|c|c|}
\hline Depth $(\mathrm{m})$ & Sample & Bottle & $\delta^{13} \mathrm{C}(\%)$ & $\mathrm{fm}$ \\
\hline \hline 470 & 1 & 1273 & 0.711 & \\
\hline 470 & 2 & 1274 & 0.701 & \\
\hline 470 & 3 & 1276 & 0.702 & \\
\hline 4000 & 4 & 1269 & 0.898 & 0.9141 \\
\hline 4000 & 5 & 1268 & 0.924 & 0.9200 \\
\hline 4000 & 6 & 1267 & 0.916 & 0.9123 \\
\hline
\end{tabular}

Table 2. Stable and radiocarbon isotope data for shallow and deep Atlantic samples processed by REDICS

\begin{tabular}{|c|c|c|c|c|c|c|}
\hline Depth (m) & Sample & Bottle & $\delta^{13} \mathrm{C}(\%$ o $)$ & $\mathrm{fm}$ & $\begin{array}{c}\mathrm{ACO}_{2} \\
\text { Traps }\end{array}$ & Notes \\
\hline \hline 470 & 1 & 1275 & 0.664 & & 1 & sample loss \\
\hline 470 & 2 & 1275 & 0.662 & & 1 & sample loss \\
\hline 470 & 15 & 1278 & 0.658 & & 1 & valve failure \\
\hline 470 & 16 & 1278 & 0.596 & & 1 & small sample \\
\hline 470 & 17 & 1277 & 0.713 & & 2 & none \\
\hline 470 & 18 & 1277 & 0.730 & & 2 & none \\
\hline 470 & 19 & 1277 & 0.724 & & 2 & none \\
\hline 470 & 20 & 1277 & 0.712 & & 2 & none \\
\hline 470 & 21 & 1279 & 0.588 & & 2 & trapped water \\
\hline 470 & 22 & 1279 & 0.683 & & 2 & trapped water \\
\hline 470 & 23 & 1279 & 0.694 & & 2 & trapped water \\
\hline 470 & 28 & 3577 & 0.695 & & 2 & none \\
\hline 470 & 29 & 3577 & 0.713 & & 2 & none \\
\hline 4000 & 3 & 1266 & 0.969 & & 1 & sample loss \\
\hline 4000 & 4 & 1266 & 0.957 & & 1 & sample loss \\
\hline 4000 & 5 & 1266 & 1.037 & & 1 & sample loss \\
\hline 4000 & 6 & 1266 & 1.046 & & 1 & sample loss \\
\hline 4000 & 7 & 1270 & 0.854 & & 1 & sample loss \\
\hline
\end{tabular}




\begin{tabular}{||c|c|c|c|c|c|c||}
\hline 4000 & 8 & 1270 & 0.860 & & 1 & sample loss \\
\hline 4000 & 9 & 1270 & 0.884 & & 1 & sample loss \\
\hline 4000 & 10 & 1270 & 0.931 & & 1 & sample loss \\
\hline 4000 & 11 & 1271 & 1.043 & 0.9244 & 1 & sample loss \\
\hline 4000 & 12 & 1271 & 1.007 & 0.9317 & 1 & sample loss \\
\hline 4000 & 13 & 1271 & 0.964 & 0.9241 & 1 & sample loss \\
\hline 4000 & 14 & 1271 & 0.932 & 0.9259 & 1 & sample loss \\
\hline 4000 & 24 & 1272 & 0.998 & & 2 & trapped water \\
\hline 4000 & 25 & 3568 & 0.987 & & 2 & none \\
\hline 4000 & 26 & 3568 & 1.031 & & 2 & none \\
\hline 4000 & 27 & 3568 & 1.004 & & 2 & none \\
\hline 4000 & 30 & 3569 & 1.019 & & 2 & none \\
\hline 4000 & 31 & 3569 & 1.007 & & 2 & none \\
\hline
\end{tabular}

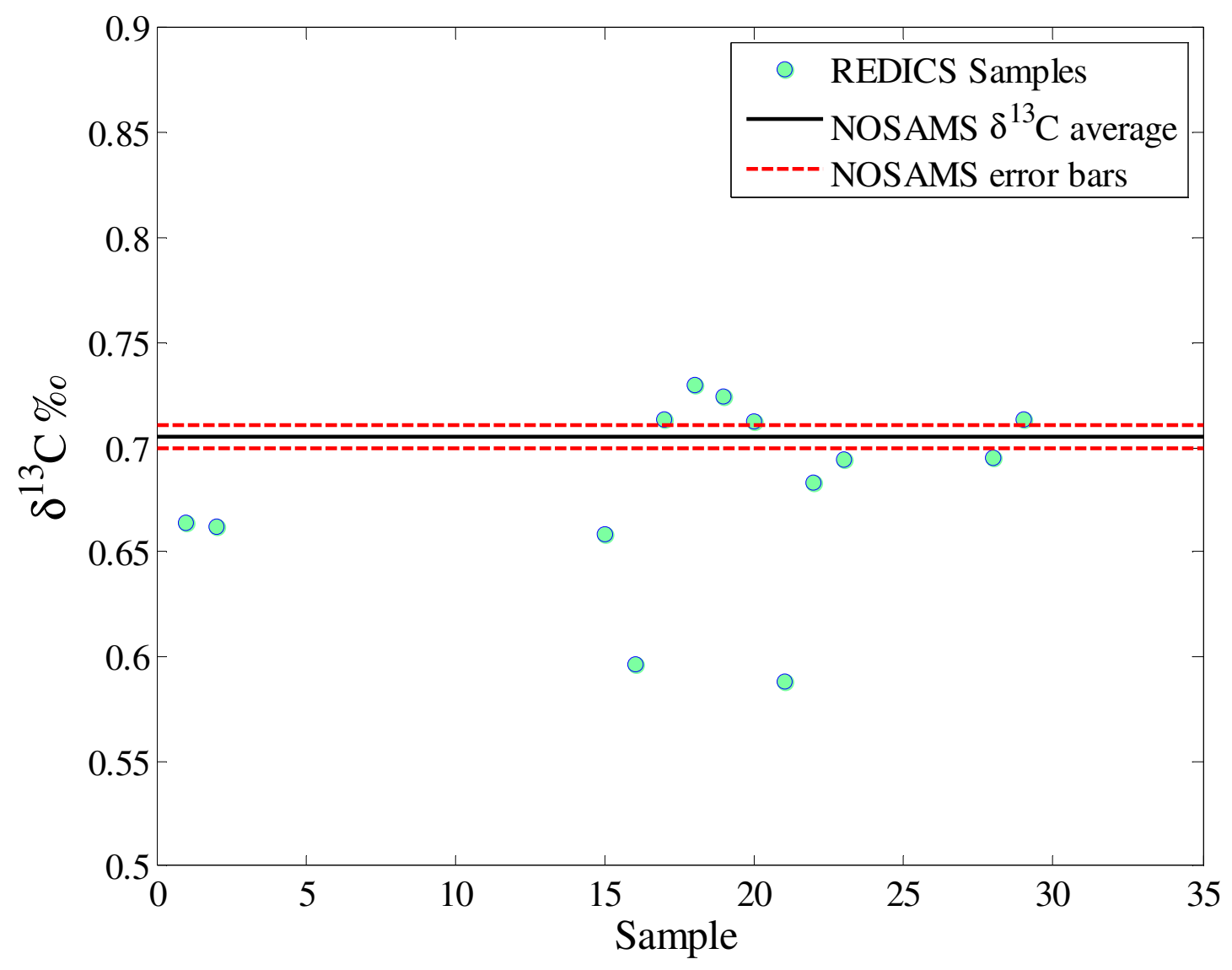

Fig 15. REDICS shallow samples stable isotope results vs. WSL results 


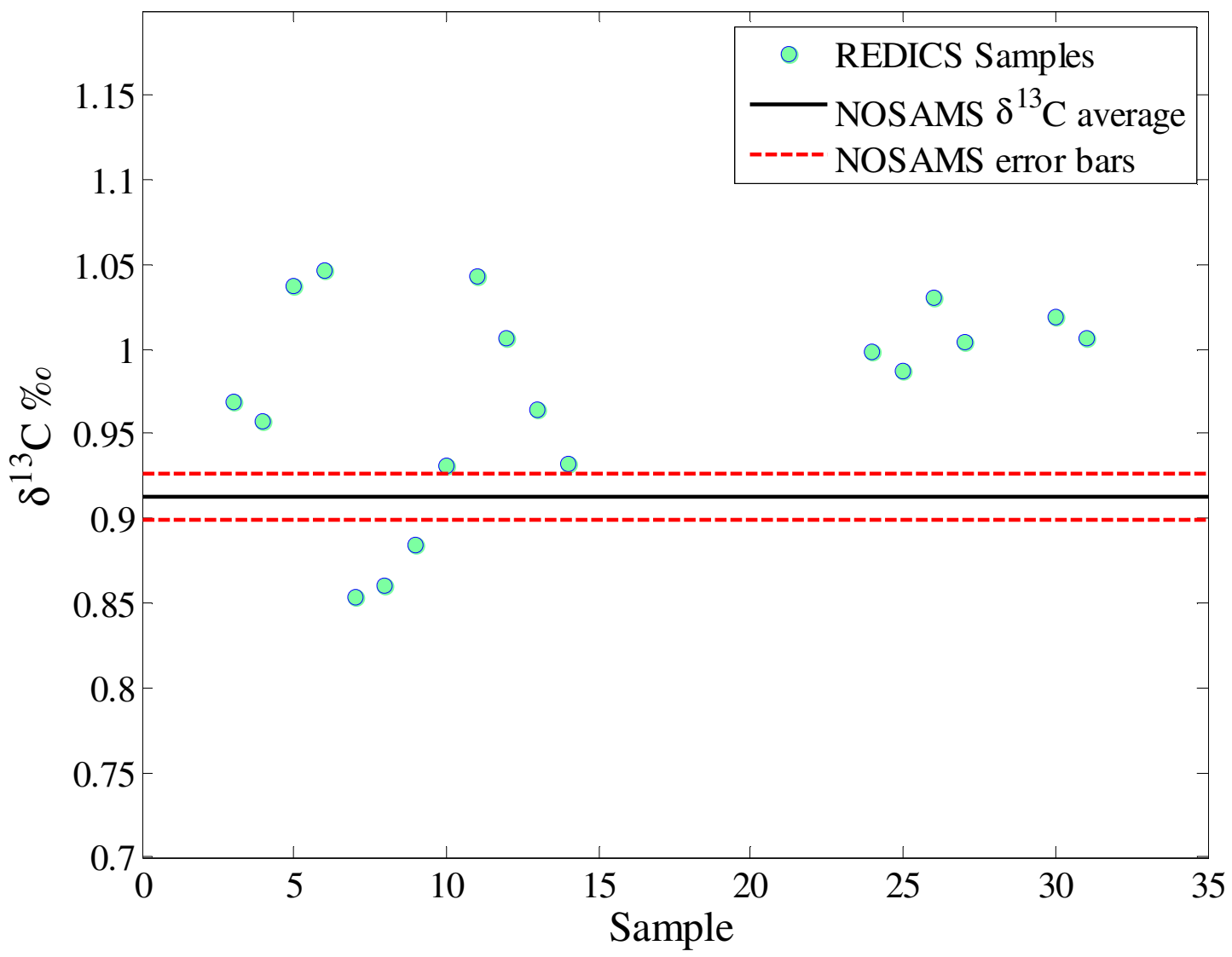

Fig 16. REDICS deep samples stable isotope results vs. WSL results

The notes column in Table 2 details the procedural problems that were identified during the development of the set up and procedures used to establish REDICS as a robust processing method. Among the earlier samples, a number were compromised in some fashion, and during subsequent runs, these issues were resolved by making improvements to the processing steps. Overall 11 (samples 17-20 and 25-31) of the samples were run without any known anomalies, and the other 20 were compromised as described below.

The first 14 water samples processed on REDICS were trapped using only one $\mathrm{CO}_{2}$ trap, and the stable isotope results from these samples suggested that sample fractionation was occurring during the sample processing. As mentioned in the system components section, the $\mathrm{CO}_{2}$ analyzer was used to determine that the single trap was only collecting approx- 
imately $90 \%$ of the $\mathrm{CO}_{2}$, and this problem was fixed by including another multi-loop trap in the TQS subsystem.

Sample 15 was compromised due to a valve not being closed all the way when isolating the two $\mathrm{CO}_{2}$ traps after trapping, which may have introduced some atmospheric $\mathrm{CO}_{2}$ to the trapped sample. The $\delta^{13} \mathrm{C}$ of the sample was lower than expected, indicating that this assumption is likely correct. Sample 16 was compromised due to the sample volume being too small to flush the sample loop.

A lot of water was trapped with samples 21-24 due to a procedure error involving the system being run prior to sample analysis without installing the isopropanol/dry ice water trap. The water in the stored $\mathrm{CO}_{2}$ samples was then transferred into the stable isotope ratio mass spectrometer and made it impossible to measure the isotope ratio. A portion of each gas sample was recovered, cryogenically dried, and re-analyzed.

Table 3 and Table 4 summarize the stable and radiocarbon results of all the samples from both systems. In addition, the last two lines in Table 3 highlight the statistical data for the samples processed on the REDICS system that were not compromised.

Table 3. Average of water sample stable isotope analyses

\begin{tabular}{|c|c|c|c|c|}
\hline System & Depth $(\mathrm{m})$ & N Samples & $\delta^{13} \mathrm{C}$ Ave $(\% o)$ & $\delta^{13} \mathrm{C}$ StDev (\%o) \\
\hline NOSAMS WSL & 470 & 3 & 0.705 & 0.006 \\
\hline NOSAMS WSL & 4000 & 3 & 0.913 & 0.013 \\
\hline REDICS & 470 & 13 & 0.680 & 0.045 \\
\hline REDICS & 4000 & 18 & 0.974 & 0.061 \\
\hline REDICS & 470 & $6(17-20,28,29)$ & 0.715 & 0.012 \\
\hline REDICS & 4000 & $5(25-27,30,31)$ & 1.010 & 0.017 \\
\hline
\end{tabular}

Table 4. Average of water sample radiocarbon isotope analyses

\begin{tabular}{|c|c|c|c|c|}
\hline System & Depth $(\mathrm{m})$ & N Samples & fm Ave & fm StDev \\
\hline NOSAMS WSL & 4000 & 3 & 0.9155 & 0.0040 \\
\hline REDICS & 4000 & 4 & 0.9265 & 0.0035 \\
\hline
\end{tabular}

The results from REDICS and NOSAMS were compared using a t-test for small samples (less than 30 data points) (Massart, Vandeginste, Deming, \& Kaufman, 1988). The test 
requires two conditions to be fulfilled in order to be applicable. First, the two sets of data must be normally distributed. Since there are not enough data points in the data sets to plot a meaningful histogram, an even distribution of points was simply confirmed visually for each of the data sets. Second, the variances of the two populations being compared should be the same. This condition is verified with an F-test, which consists of calculating the ratio of the squared variances and comparing the values to an F-distribution which typically uses tolerance of $\alpha=0.05$ (Table 5, Table 6). If the calculated ratios are smaller, the hypothesis that the variances match is accepted, and the t-test can be further performed. Traditionally the larger variance is divided by the smaller variance for the F-test.

Table 5. F-test comparison stable isotope data sets

\begin{tabular}{|c|c|c|c|c|c|}
\hline System & Depth (m) & N Samples & $\begin{array}{c}\delta^{13} \mathrm{C} \mathrm{StDev} \\
\mathrm{s}(\% \circ)\end{array}$ & $\mathrm{F}=\mathrm{s}_{1} / \mathrm{s}_{2}$ & $\begin{array}{l}\mathrm{F}(\alpha=0.05) \\
\text { Distribution }\end{array}$ \\
\hline WSL & 470 & 3 & $\overline{\mathrm{s}_{2}=0.006}$ & \multirow{2}{*}{56.25} & \multirow{2}{*}{39.41} \\
\hline REDICS & 470 & 13 & $s_{1}=0.045$ & & \\
\hline WSL & 4000 & 3 & $s_{2}=0.013$ & \multirow{2}{*}{22.02} & \multirow{2}{*}{39.44} \\
\hline REDICS & 4000 & 18 & $s_{1}=0.061$ & & \\
\hline WSL & 470 & 3 & $\mathrm{~s}_{2}=0.006$ & \multirow{2}{*}{4.00} & \multirow{2}{*}{39.30} \\
\hline REDICS & 470 & $6(17-20,28,29)$ & $\mathrm{s}_{1}=0.012$ & & \\
\hline WSL & 4000 & 3 & $\mathrm{~s}_{2}=0.013$ & \multirow{2}{*}{1.71} & \multirow{2}{*}{39.25} \\
\hline REDICS & 4000 & $5(25-27,30,31)$ & $\mathrm{s}_{1}=0.017$ & & \\
\hline
\end{tabular}

Table 6. F-test comparison of radiocarbon data sets

\begin{tabular}{|c|c|c|c|c|c||}
\hline System & Depth $(\mathrm{m})$ & N Samples & fm St Dev & $\mathrm{F}=\mathrm{s}_{1} / \mathrm{s}_{2}$ & $\begin{array}{c}\mathrm{F} \\
\text { Distribution }\end{array}$ \\
\hline WSL & 4000 & 3 & $\mathrm{~s}_{2}=0.004$ & 1 & 19.16 \\
\hline REDICS & 4000 & 4 & $\mathrm{~s}_{1}=0.004$ & 1 & 16 \\
\hline
\end{tabular}

The $\mathrm{F}$ distribution values show that the variances of the full shallow water sample data sets differ, so the t-test is not applicable for the data comparison. This is likely due to the fact that compromised samples were included in this data set and to the unusually small variance observed in the WSL dataset.

The remaining data sets meet the two conditions for validity and are further analyzed using a t-test. The t-test statistic is calculated using Eqn 21: 


$$
t=\frac{\bar{x}_{1}-\bar{x}_{2}}{\sqrt{s^{2}\left(\frac{1}{n_{1}}+\frac{1}{n_{2}}\right)}}
$$

where $\overline{\mathrm{x}}$ is the mean, $\mathrm{n}$ is size, and $\mathrm{s}$ is the pooled variance obtained by:

$$
s^{2}=\frac{\left(n_{1}-1\right) s_{1}^{2}+\left(n_{2}-1\right) s_{2}^{2}}{n_{1}+n_{2}-2}
$$

The calculated t-values are then compared to theoretical t values at a significance level $\alpha$ $=0.05$ and $n_{2}+n_{1}-2$ degrees of freedom.

\begin{tabular}{|c|c|c|c|c|c|}
\hline System & Depth (m) & N Samples & $\mathrm{s}^{2}$ & $\mathrm{t}$ & $\mathrm{t}$ theoretical \\
\hline WSL & 4000 & 3 & \multirow{2}{*}{$3.30 \mathrm{e}-3$} & \multirow{2}{*}{1.69} & \multirow{2}{*}{2.09} \\
\hline REDICS & 4000 & 18 & & & \\
\hline WSL & 470 & 3 & \multirow{2}{*}{$0.11 \mathrm{e}-3$} & \multirow{2}{*}{1.20} & \multirow{2}{*}{2.37} \\
\hline REDICS & 470 & $6(17-20,28,29)$ & & & \\
\hline WSL & 4000 & 3 & \multirow{2}{*}{$0.25 \mathrm{e}-3$} & \multirow{2}{*}{8.42} & \multirow{2}{*}{2.45} \\
\hline REDICS & 4000 & $5(25-27,30,31)$ & & & \\
\hline
\end{tabular}

Table 7. T-test comparison stable isotope data sets

Table 8. T-test comparison of radiocarbon data sets

\begin{tabular}{||c|c|c|c|c|c||}
\hline System & Depth $(\mathrm{m})$ & N Samples & $\mathrm{s}^{2}$ & $\mathrm{t}$ & $\mathrm{t}$ theoretical \\
\hline \hline WSL & 4000 & 3 & \multirow{2}{*}{$1.6 \mathrm{e}-5$} & 4.71 & 2.57 \\
\hline REDICS & 4000 & 4 & & & \multirow{2}{*}{${ }^{2}$} \\
\hline
\end{tabular}

\subsection{Results Discussion}

\subsubsection{Shallow water standards $\delta^{13} \mathrm{C}$ results}

As described above, the full shallow dataset from the REDICS system could not be statistically compared to the WSL dataset due to difference in data set variances. Therefore, the reduced dataset consisting of the uncompromised REDICS shallow samples was compared to the WSL results, and the results are plotted in Fig 17. 


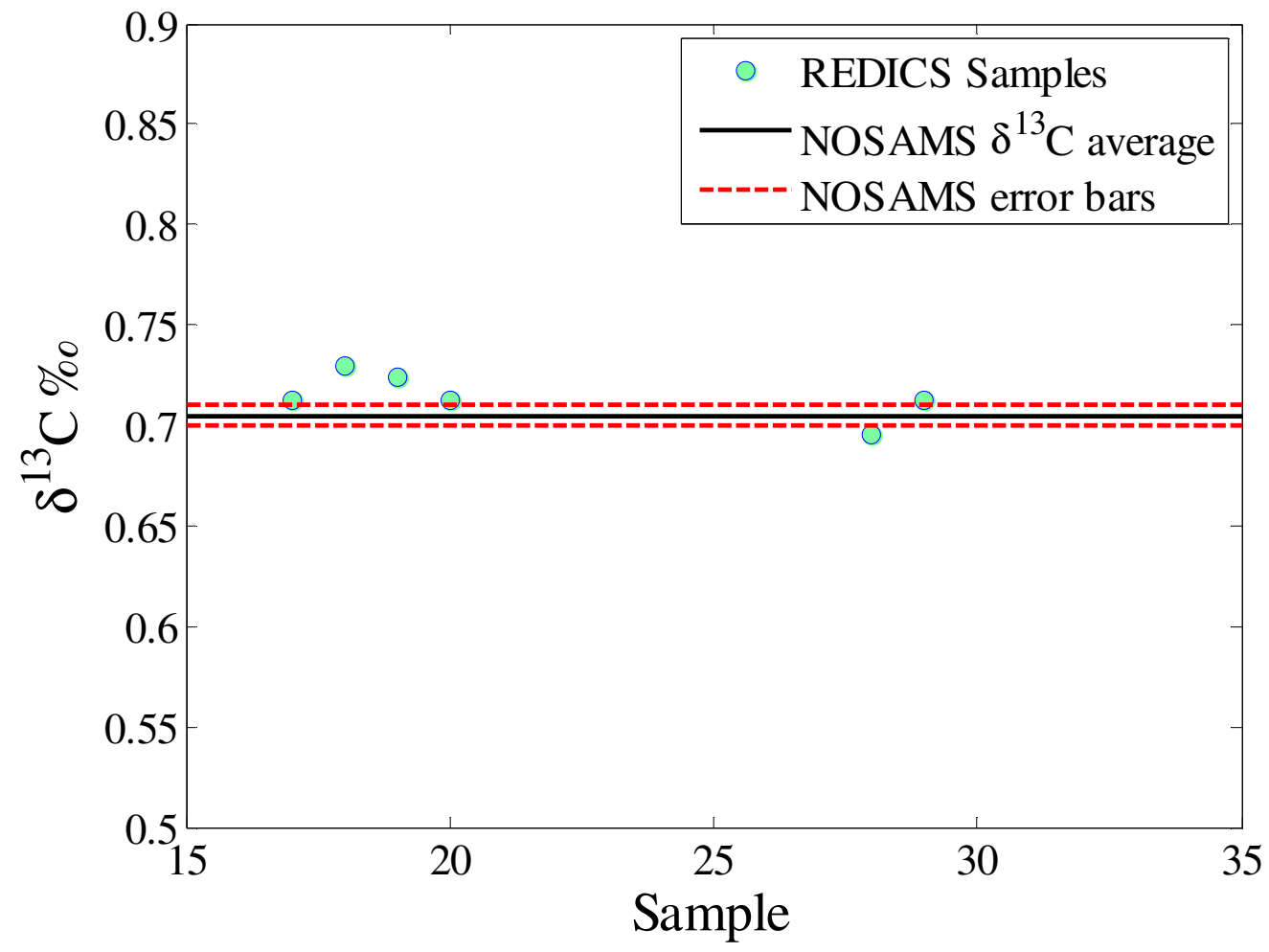

Fig 17. REDICS shallow (not compromised) samples stable isotope results

The t-test (Table 7) shows that the two datasets are consistent. Furthermore the precision and accuracy are both very good since the standard deviation is only $0.012 \% \circ$ and the mean values differ by only $0.010 \%$. Even though the datasets are small, this is strong evidence that the REDICS system is robust. However, it is still important that more data be obtained to verify this result. It is also expected that the precision will deteriorate as the dataset size increases.

\subsubsection{Deep water standards $\delta^{13} \mathrm{C}$ results}

The stable isotope results for deep water samples were compared as well. The large variance of $0.061 \%$ o seen in the full REDICS deep water dataset is likely due to the inclusion of compromised data. However, the t-test (Table 7) indicates that the WSL dataset and the full REDICS dataset are consistent. This result is somewhat surprising, since it was expected that the compromised tests would have made the datasets less consistent. 
The fact that they were consistent is encouraging, since it shows that the REDICS system still functioned well even when it had not been optimized.

The uncompromised deep water sample dataset was also compared to the WSL deep water samples (Fig 18). In contrast to the full dataset, the t-test for these results did not show consistency with the WSL datasets. The inconsistency was primarily due to a difference in mean values. It is hypothesized that this offset is likely due to the small size of the datasets, and that with more points the means will converge. It is also important to note that both the REDICS and the WSL datasets have very high precision, higher than NOSAMS observes routinely.

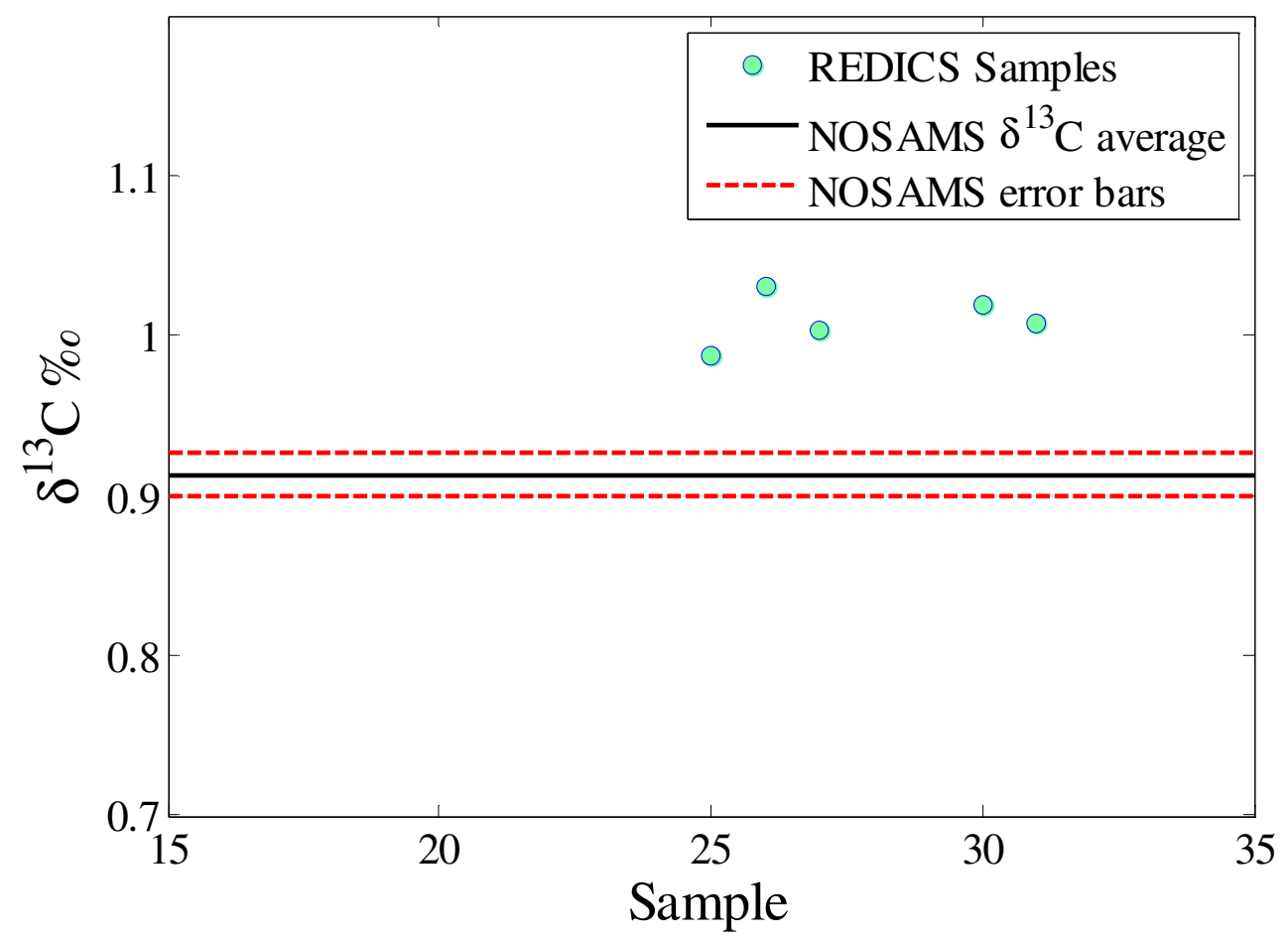

Fig 18. REDICS deep (not compromised) samples stable isotope results

Other factors that may contribute to the offset are discussed here. It is possible that small amounts of extraneous carbon are added while processing the samples on REDICS, what is often referred to as process blank. It is difficult to reconcile the data presented in Fig 17 and Fig 18 with this explanation. The results from the deep samples suggest that the carbon added must have a $\delta^{13} \mathrm{C}$ value enriched in ${ }^{13} \mathrm{C}$ relative to the sample. Adding the 
same carbon to the shallow samples, which are more depleted in ${ }^{13} \mathrm{C}$ than the deep samples, should create an even larger difference between the means than is observed in the deep samples.

Another possibility is that gases other than $\mathrm{CO}_{2}$ are being transferred across the membrane and trapped with the $\mathrm{CO}_{2}$. In the atmosphere, prior to making stable isotope measurements, $\mathrm{N}_{2} \mathrm{O}$ must be removed from the sample or corrected for afterwards. $\mathrm{N}_{2} \mathrm{O}$ has the same molar mass as $\mathrm{CO}_{2}$ and is also cryogenically trapped by $\mathrm{LN}_{2}$ (Fig 4). Thus, its presence, in significant quantities in the deep water samples and relative absence in the shallow water samples, could affect the ${ }^{13} \mathrm{C}$ measurements from the mass spectrometer. However, the typical levels of $\mathrm{N}_{2} \mathrm{O}$ (up to $0.23 \mu \mathrm{mols} / \mathrm{L}$ ) found in seawater (Yoshinari, 1976) are four orders of magnitude lower than the level of $\mathrm{CO}_{2}(2 \mathrm{mmol} / \mathrm{L})$, and this fact alone makes it very unlikely that it's the cause for the offset. Additionally, given the mechanism of the gas transfer across the LiquiCel membrane, it is not clear how it would be possible for the REDICS system to differ greatly in the treatment of $\mathrm{N}_{2} \mathrm{O}$, and other gases that might cryogenically mask as $\mathrm{CO}_{2}$, from the NOSAMS' system. However, in order to completely eliminate $\mathrm{N}_{2} \mathrm{O}$ as a potential factor, the levels of $\mathrm{N}_{2} \mathrm{O}$ in the samples would need to be experimentally measured, and it would also be beneficial to characterize the $\mathrm{N}_{2} \mathrm{O}$ properties of the Liqui-Cel contractor.

Comparing the REDICS and NOSAMS deep water $\delta^{13} \mathrm{C}$ results to results obtained from seawater collected at a nearby CLIVAR station in 1997 (A20, latitude $=8.48^{\circ}$, longitude $\left.=-52.81^{\circ}\right)($ Table 9) suggests the REDICS data are more consistent with historical data.

Table 9. Average of water sample stable isotope analyses

\begin{tabular}{|c|c|c|c|c||}
\hline \hline System & Depth $(\mathrm{m})$ & N Samples & $\delta^{13}$ C Ave (\%o) & $\delta^{13}$ C StDev (\%o) \\
\hline \hline CLIVAR & 3020 & 5 & 1.134 & 0.011 \\
\hline REDICS & 4000 & 5 & 1.010 & 0.017 \\
\hline NOSAMS & 4000 & 3 & 0.913 & 0.013 \\
\hline
\end{tabular}

However, the difference in station location, sampling time, and depth, make it difficult for this comparison to be robust at a high precision. It does, however, further demonstrate that the REDICS method produces oceanographically reasonable results. 


\subsubsection{Deep water standards fm results}

The radiocarbon results from the deep water did not pass the t-test and suggest that the REDICS results are enriched in ${ }^{14} \mathrm{C}$ relative to the NOSAMS' results.

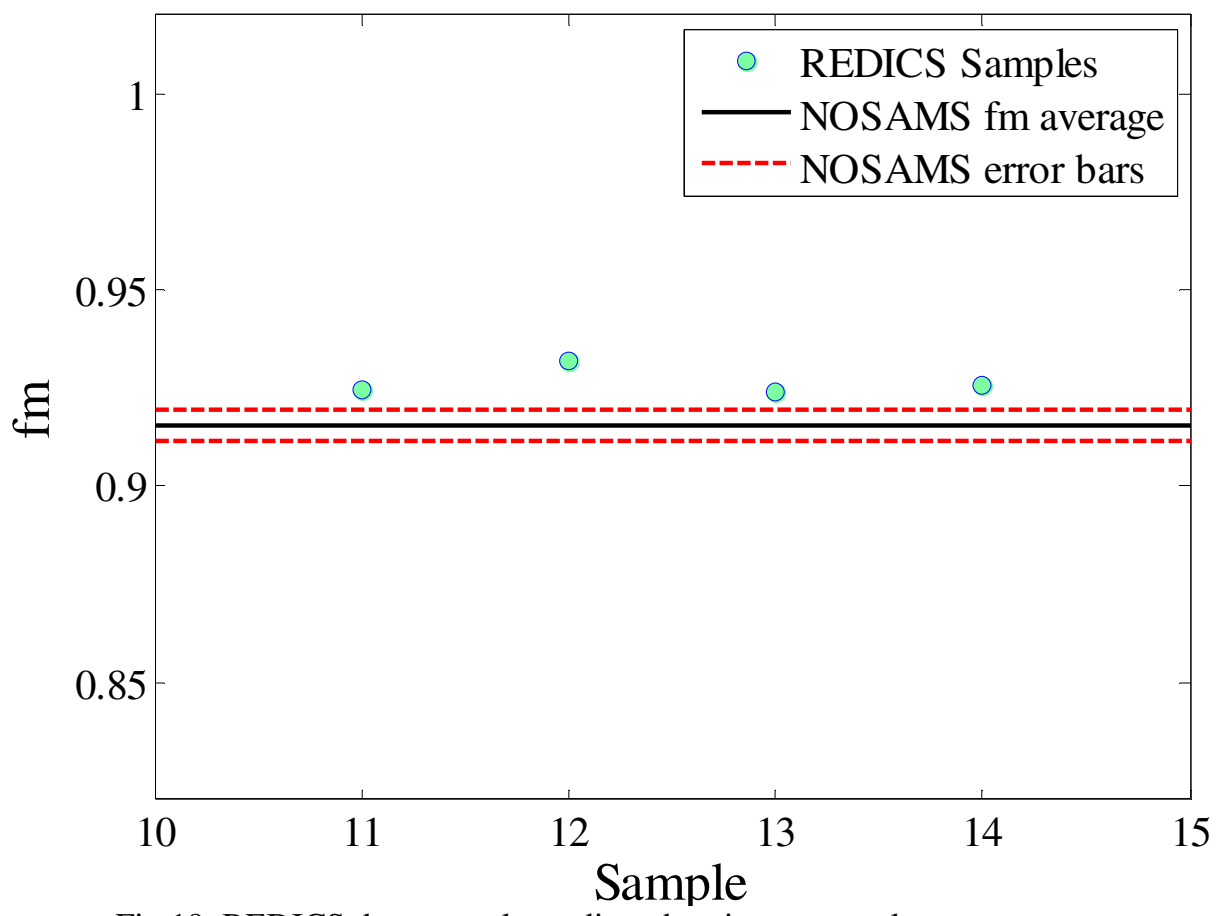

Fig 19. REDICS deep samples radiocarbon isotope results

Comparing the REDICS and NOSAMS radiocarbon results to the CLIVAR data (Table 10) also indicates that the REDICS results are enriched in ${ }^{14} \mathrm{C}$. It is likely that the limited number of data points makes a robust comparison difficult, and additional points need to be acquired draw further conclusions.

Table 10. Average of water sample radiocarbon isotope analyses

\begin{tabular}{|c|c|c|c|c|}
\hline System & Depth $(\mathrm{m})$ & N Samples & fm Ave & fm StDev \\
\hline \hline CLIVAR & 3020 & 5 & 0.9180 & 0.0036 \\
\hline REDICS & 4000 & 4 & 0.9265 & 0.0035 \\
\hline NOSAMS & 4000 & 3 & 0.9155 & 0.0040 \\
\hline
\end{tabular}




\subsubsection{Results summary}

Overall, the results of the REDICS tests were significantly influenced by the small size of the datasets, which gave them unusually high precision within each dataset and low consistency between different datasets. In comparison, previously analyzed seawater standards have the following precision:

Table 11. WSL statistical summary of water sample stable isotope analyses

\begin{tabular}{|c|c|c|c|c|}
\hline System & Standard & N Samples & $\delta^{13}$ C StDev (\%o) & fm StDev \\
\hline \hline NOSAMS WSL & OCE_455 & 87 & 0.042 & 0.008 \\
\hline NOSAMS WSL & STA 15 & 3 & 0.006 & 0.004 \\
\hline
\end{tabular}

Even though the current datasets were limited in size, the data from these preliminary tests are encouraging, and it is expected that as larger sets of data become available, the systems' results will become more statistically similar. Further conclusions will be able to be drawn about the REDICS performance when a more robust sample set is available for analysis. 


\section{FUTURE IMPROVEMENTS}

\subsection{Multiple sample analysis}

Although it has not yet been done, the system can easily be adapted to analyze multiple samples in series using a Valco Cheminert 10 port selector valve for sample introduction (Fig 20). In this configuration, all lines will be flushed with MilliQ water between sample analyses to prevent cross contamination. The ten samples will be placed in a nitrogen gas glove box, which will allow for the sample to be displaced with $\mathrm{CO}_{2}$ free nitrogen gas upon introduction to the system.

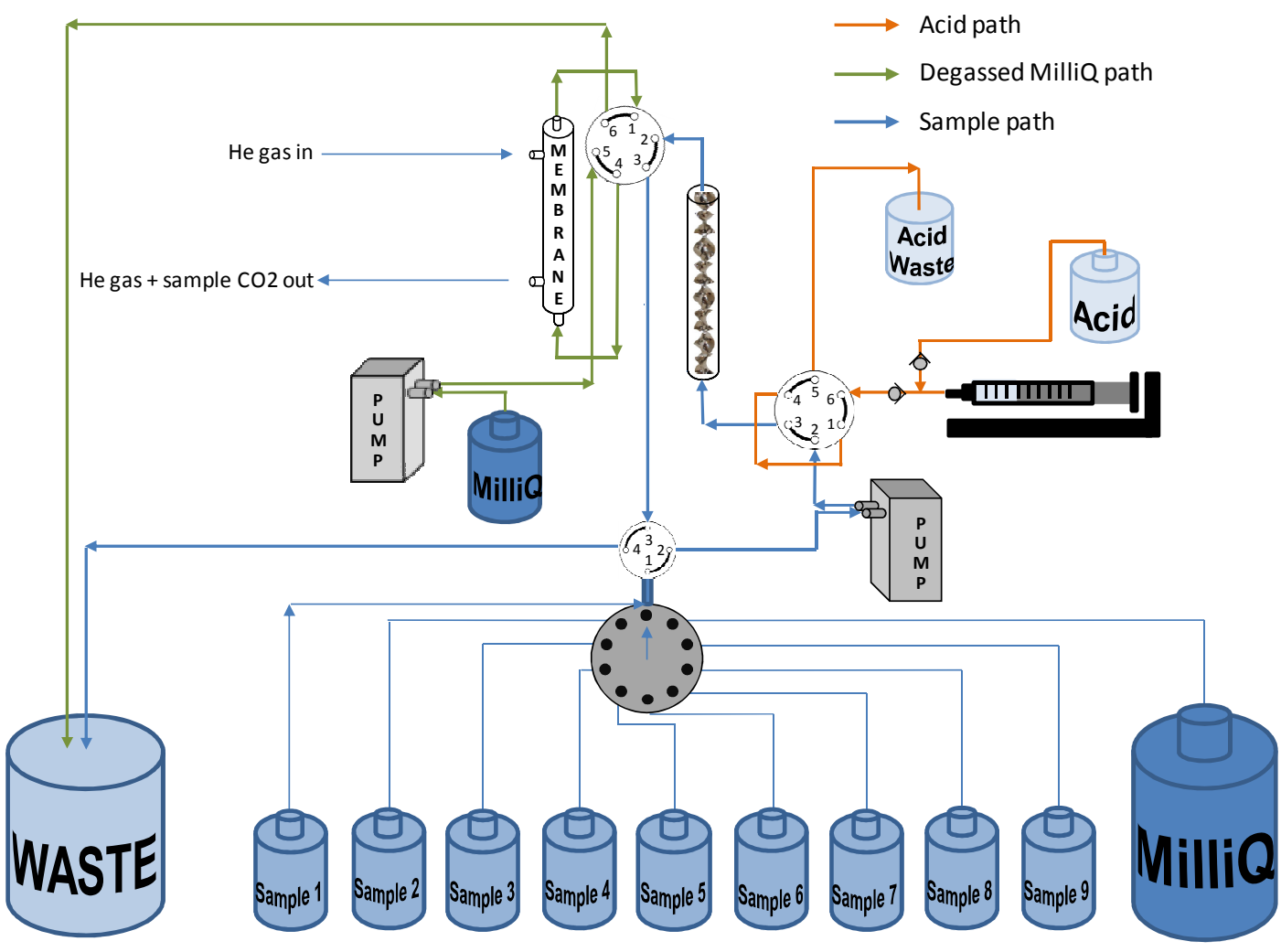

Fig 20. Multiple sample analysis.

\section{2. $\mathrm{CO}_{2}$ trapping}

The $\mathrm{CO}_{2}$ is currently extracted from the water sample at high flow rates $(1 \mathrm{~L} / \mathrm{min})$, which may have an effect on the trapping efficiency of the cryogenic traps. Thus, to ensure 
complete extraction of the sample DIC and prevent the risk of sample fractionation, it is recommended that a recirculating pump be added to the sample quantification and storing subsystem. A more efficient thin-walled stainless steel multi-loop $\mathrm{LN}_{2}$ trap is considered as well.

Another approach to mitigate loss of sample is to use a different membrane contractor that operates at lower flow rates. For instance, the Liqui-Cel Micromodule allows for sweep gas flow rates in the $50 \mathrm{ml} / \mathrm{min}-500 \mathrm{ml} / \mathrm{min}$ range and may be another appropriate choice for the extraction system.

\subsection{Parallel sample quantification and storing}

The carbon dioxide is extracted by the membrane contractor in less than 4 minutes. However, the quantification and storing of the sample can take up to $15-20$ minutes. Thus to make the system more efficient, multiple quantifying and storing subsystems can be added in parallel.

\subsection{Automation - control and fault protection}

REDICS can also be fully automated since all of the components can be digitally controlled. This will decrease sample processing time and manual labor. Rigorous fault protection can also help ensure the correct and safe operation of the system as well as the preservation of clients' samples and system components. The system's control can be implemented in LabVIEW which is used by all sample preparation lines in NOSAMS thus making it very accessible. 


\section{CONCLUSIONS}

REDICS was designed to efficiently extract DIC from water samples in the form of $\mathrm{CO}_{2}$, trap the extracted gas cryogenically, quantify it, and store it for further analysis. The $\mathrm{CO}_{2}$ extraction is achieved using commercial microporous contractor, which extracts the sample in less than 4 minutes. The system was tested using shallow and deep seawater standards. The stable and radiocarbon isotope values of the extracted gas samples were determined and compared to the values of the same standards analyzed on the NOSAMS WSL. This comparison, along with system validation, was used to evaluate REDICS performance. The results demonstrate that the system successfully extracts more than $99 \%$ of the dissolved inorganic carbon in less than 20 minutes. Stable isotope and radiocarbon isotope analyses demonstrated system precision of $0.02 \%$ and $3.5 \%$ respectively. An offset between the REDICS AND WSL datasets was noticed in the deep water sample analysis, both in the $\delta^{13} \mathrm{C}$ and radiocarbon values, which could be an artifact of the small size of the data sets. These discrepancies need to be further investigated by obtaining larger and more robust sample datasets. 


\section{Bibliography}

1. Baker, R. (2004). Membrane Technology and Applications. John Wiley \& Sons, Ltd.

2. Bandstra, L., Hales, B., \& Takahashi, T. (2006). High-frequency measurements of total CO2: Method developement and first oceanographic observations. Marine Chemistry, 100, 24-38.

3. Cohen, G., Hutton, D., Osborne, E., von Reden, K., Gagnon, A., McNichol, A., et al. (1994). Automated sample processing at the National Ocean Sciences AMS Facility. Nuclear Instruments and Methods in Physics Research B , 92, 129-133.

4. De Candia, F., \& Vittoria, V. (1994). Permeability of PEEK to carbon dioxide. Journal of Applied Polymer Science , 51, 2103-2107.

5. Doney, S., Tilbrook, B., Roy, S., Metzl, N., Le Quéré, C., Hood, M., et al. (2009). Surface - ocean CO2 variability and vulnerability. Deep Sea Research Part II: Topical Studies in Oceanography, 56, 504-511.

6. Elder, K., McNichol, A., \& A.R., G. (1998). Reproducibility of seawater, inorganic and organic carbon $14 \mathrm{C}$ results at NOSAMS. Radiocarbon, 40, 223230.

7. Feron, P., \& Jansen, A. K. (1992). Membrane technology in carbon dioxide removal. Energy Conversion and Management , 33, 421 - 428.

8. Gabelman, A., \& Hwang, S. (1999). Hollow fiber membrane contractors. Journal of Membrane Science, 61.

9. Godwin, H. (1962). Half life of radiocarbon. Nature , 195, 984.

10. Hales, B., Chipman, D., \& Takahashi, T. (2004). High-frequency measurement of partial pressure and total concentration of carbon dioxide in seawater using microporous hydrophobic membrane contractors. Limnology and Oceanography:Methods, 356-364.

11. Kenneth, J. (1982). Marine Geology. Englewood Cliffs: PRENTICE-HALL.

12. Kim, B. H. (1987). Critical entry pressure for liquids in hydrophobic membranes. Journal of Colloid and Interface Science , 115, 1910 - 1916.

13. Libby, W. F., \& Arnold, J. R. (1949). Age determinations by radiocarbon content: checks with samples of known age. Science, 110, 670-680.

14. Libby, W. (1961). Radiocarbon Dating. Science , 621-629.

15. Lide, D. R. (1995). CRC Handbook of Chemistry \& Physics. CRC Press.

16. Liqui-Cel, M. (n.d.). Design and Operating Procedures. Retrieved from LiquiCel: www.liqui-cel.com 
17. Liqui-Cel, M. (n.d.). Membrane Contractors - Introduction to the Technology. Retrieved from Liqui-Cel: www.liqui-cel.com

18. Liqui-Cel, M. (n.d.). MiniModule Data Sheet. Retrieved from Liqui-Cel: www.liqui-cel.com

19. Massart, D., Vandeginste, S., Deming, Y., \& Kaufman, L. (1988). Chemometrics: a textbook. Amsterdam, Oxford, New York, Tokyo: ELSEVIER.

20. McNichol, A., \& Aluwihare, L. (2007). The Power of Radiocarbon in Biogeochemical Studies of the Marine Carbon Cycle: Insights from Studies of Dissolved and Particulate Organic Carbon (DOC and POC). Chemistry Review, 107, 443-466.

21. McNichol, A., Jones, G., Hutton, D., \& Gagnon, A. (1994). The rapid preparation of seawater $\sum \mathrm{CO} 2$ for radiocarbon analysis at the National Ocean Sciences AMS Facility. Radiocarbon, 36, 237 - 246.

22. McNichol, A., Schneider, R., von Reden, K., Gagnon, A., Elder, K., NOSAMS, et al. (2000). Ten years after - the WOCE AMS radicarbon program. Nuclear Instruments and Methods in Physical Research B , 172, 479-484.

23. Meyer, H., \& Gamez, J. (1995). Gas separation membranes: coming of age for carbon dioxide removal from natural gas. Laurence Reid Gas Conditioning Conference, (p. 284). Oklahoma.

24. Mulder, M. (1992). Basic Principles in Membrane Technology. Kluwer Academic Publishers.

25. Peng, T.-H., Key, R. M., \& Östlund, H. (1997). Temporal variations of bomb radiocarbon inventory in the Pacific ocean. Marine Chemistry, 60, 3-13.

26. Reed, B., Semmens, M., \& Cussler, E. (1995). Chapter 10 in Membrane Separation Technology, Principles and Applications. Amsterdam: Elsevier Science.

27. Sabine, C., Feely, R., Gruber, N., Key, R., Lee, K., Bullister, J., et al. (2004). The oceanic sink for anthropogenic CO2. Science, 305, 367-371.

28. Sridha, S., Smitha, B., \& Aminabhavi, T. (2007). Separation of carbon dioxide from natural gas mixtures through polymeric membranes - A review. Separation and Purification Reviews , 36, 113 - 174.

29. Ulbricht, M. (2006). Advanced functional polymer membranes. Polymer , 47, $2217-2262$.

30. Wijmans, J., \& Baker, R. (1995). The solution-diffusion model: A review. Journal of Membrane Science .

31. Yang, M., \& Cussler, E. (1986). Designing Hollow-Fiber Contractors. AIChe Journal , 32, 1-5.

32. Yoshinari, T. (1976). Nitrous Oxide in the Sea. Marine Chemistry, 4, 189-202. 